\title{
Volatile Impurities in th Ceramic Form for the Plutonium Immobilization Project (PIP)
}

by
A. D. Cozzi

Westinghouse Savannah River Company

Savannah River Site

Aiken, South Carolina 29808

J. C. Marra

T. B. Edwards

J. M. Pareizs

A. R. Jurgensen

D. M. Missimer

K. G. Brown

DOE Contract No. DE-AC09-96SR18500

This paper was prepared in connection with work done under the above contract number with the U. S.

Department of Energy. By acceptance of this paper, the publisher and/or recipient acknowledges the U. $S$.

Government's right to retain a nonexclusive, royalty-free license in and to any copyright covering this paper, along with the right to reproduce and to authorize others to reproduce all or part of the copyrighted paper. 


\title{
Volatile Impurities in the Ceramic Form for the Plutonium Immobilization Project (PIP) (U)
}

\author{
A.D. Cozzi \\ J.C. Marra \\ J.M. Pareizs \\ A.R. Jurgensen \\ D.M. Missimer \\ K.G. Brown \\ T.B. Edwards
}

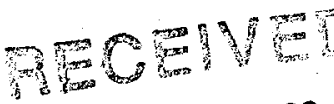

MAR 132080

Q.STI

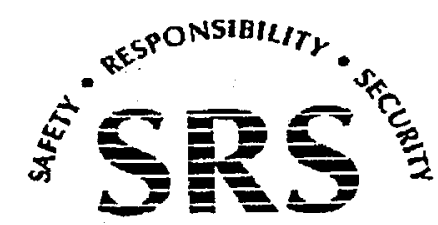




\section{DISCLAIMER}

This report was prepared as an account of work sponsored by an agency of the United States Government. Neither the United States Government nor any agency thereof, nor any of their employees, makes any warranty, express or implied, or assumes any legal liability or responsibility for the accuracy, completeness, or usefulness of any information, apparatus, product or process disclosed, or represents that its use would not infringe privately owned rights. Reference herein to any specific commercial product, process or service by trade name, trademark, manufacturer, or otherwise does not necessarily constitute or imply its endorsement, recommendation, or favoring by the United States Government or any agency thereof. The views and opinions of authors expressed herein do not necessarily state or reflect those of the United States Government or any agency thereof.

This report has been reproduced directly from the best available copy.

Available for sale to the public, in paper, from: U.S. Department of Commerce, National Technical Information Service, 5285 Port Royal Road, Springfield, VA 22161, phone: (800) 553-6847

fax: (703) 605-6900

email: orders@ntis.fedworld.gov

online ordering: http://www.ntis.gov/ordering.htm

Available electronically at http://www.doe.gov/bridge

Available for a processing fee to U.S. Department of Energy and its contractors, in paper, from: U.S. Department of Energy, Office of Scientific and Technical Information, P.O. Box 62, Oak Ridge, TN 37831-0062, phone: (865) 576-8401

fax: (865) 576-5728

email: reports@adonis.osti.gov 


\section{DISCLAIMER}

Portions of this document may be illegible in electronic image products. Images are produced from the best available original document. 
WSRC-TR-99-00479

Publication Date: January 2000

\section{Volatile Impurities in the Ceramic Form for the Plutonium Immobilization Project (PIP) (U)}

\section{Approvals}

$$
\frac{\text { Q. C. Co }}{\text { A.D. Cozzi, Author }}
$$

Gamed C. Maur J.C.Marra, Author

$\frac{1}{3 \text { Paris }}$

Q.R. Jus gense

A.R. Jurgensed, Author

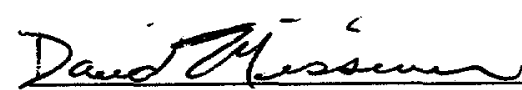

D.M. Missimer, Author

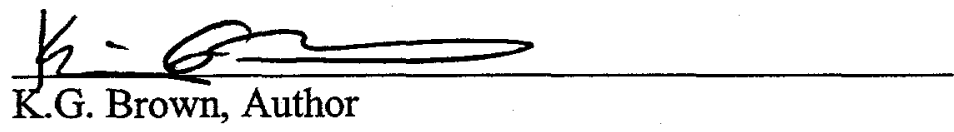

Thomes B Solwands

T.B. Edwards, Author

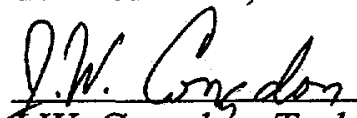

J.W. Congdón, Technical Reviewer, Materials Technology

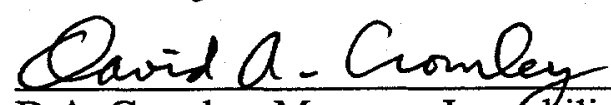

D.A. Crowley, Manager, Immobilization Technology

Qeem 2. Beareast

A.L. Blancett, Manager, Actinide Technology

$$
\begin{aligned}
& \frac{1-700}{\text { Date }} \\
& \frac{1-28-00}{\text { Date }} \\
& \frac{2-1-00}{\text { Date }} \\
& \frac{2 / 1 / 60}{\text { Date }} \\
& \frac{1-26-2000}{\text { Date }} \\
& \frac{1 / 31 / 2000}{\text { Date }} \\
& \frac{1-31-00}{\text { Date }} \\
& \frac{1-7-00}{\text { Date }} \\
& \frac{2 / 1 / 00}{\text { Date }} \\
& \frac{2 / 1 / 00}{\text { Date }}
\end{aligned}
$$

Westinghouse Savannah River Company

Savannah River Site

Aiken, SC 29808

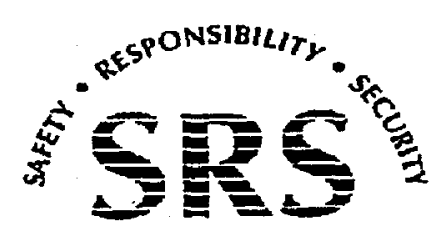

PREPARED FOR THE U.S. DEPARTMENT OF ENERGY UNDER CONTRACT NO. DE-AC09-96SR18500 
WSRC-TR-99-00479

Publication Date: January 2000

\title{
Volatile Impurities in the Ceramic Form for the Plutonium Immobilization Project (PIP) (U)
}

\author{
A.D. Cozzi \\ J.C. Marra \\ J.M. Pareizs \\ A.R. Jurgensen \\ D.M. Missimer \\ K.G. Brown \\ T.B. Edwards
}

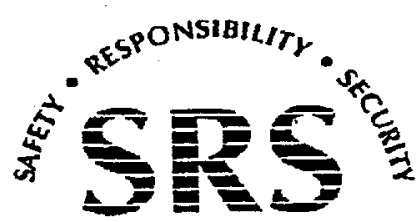




\title{
Volatile Impurities in the Ceramic Form for the Plutonium Immobilization Project (PIP) (U)
}

\author{
By A.D. Cozzi, J.C. Marra, J.M. Pareizs, A.R. Jurgensen, \\ D.M. Missimer, K.G. Brown and T.B. Edwards \\ Westinghouse Savannah River Company \\ Savannah River Site \\ Aiken, South Carolina, 29808
}

\begin{abstract}
The primary goal for the impurity tests performed at SRS was to determine the maximum level of volatile impurities that can be accommodated into the ceramic form without significantly affecting product properties. The properties investigated in this study are the apparent porosity and the phase assemblage. The volatile species anticipated in the $\mathrm{Pu}$ feed can be classified into three basic categories:

- $\quad$ Oxides (e.g., $\mathrm{PbO}, \mathrm{WO}_{3}$, and $\mathrm{ZnO}$ )

- Chlorides (e.g., $\mathrm{NaCl}, \mathrm{KCl}$, and $\mathrm{CaCl}_{2}$ )

- Fluorides (e.g., $\mathrm{CaF}_{2}$ and $\mathrm{MgF}_{2}$ )

The impurity studies were first performed with cerium as a surrogate for plutonium and uranium. These tests were repeated where cerium was only substituted for plutonium on a 1-to-1 molar basis. A subset of the tests was performed with thorium as a plutonium surrogate. A select set of the sample compositions was repeated with plutonium to verify the conclusions observed in the surrogate samples. The pellets were sintered at $1350^{\circ} \mathrm{C}$ for $4 \mathrm{hr}$ in air. All of the pellets were prepared using a cold press and sinter process.

Single additions of impurities caused formation of phases that were not present in the impurity-free reference pellets. However, all of the phases formed were present in amount identified as acceptable based upon the mineralogy specifications set forth in the baseline formulation report ${ }^{1}$. In comparison to single impurity additions, simultaneous additions of multiple impurities reduced the number of ancillary phases as well as the relative amounts of these resulting phases. The total amount of impurities added during the simultaneous additions ( 0.6 moles impurity per mole plutonium) was equivalent to the amount of each of the singularly added impurities. Densification, as measured by apparent porosity, was significantly affected by eleven of the fifteen impurities. Sodium chloride was the only compound to significantly decrease the density of the ceramic. Additions of $\mathrm{MgCl}_{2}, \mathrm{ZnCl}_{2}, \mathrm{MgF}_{2}$ and $\mathrm{CaF}_{2}$ had no discernible effect on the density of the form. Several two-factor interactions were significant in either increasing or decreasing the apparent porosity of the ceramic. However, the data were not sufficient for a definitive assessment of the importance of the interactions.
\end{abstract}




\section{Table Of Contents}

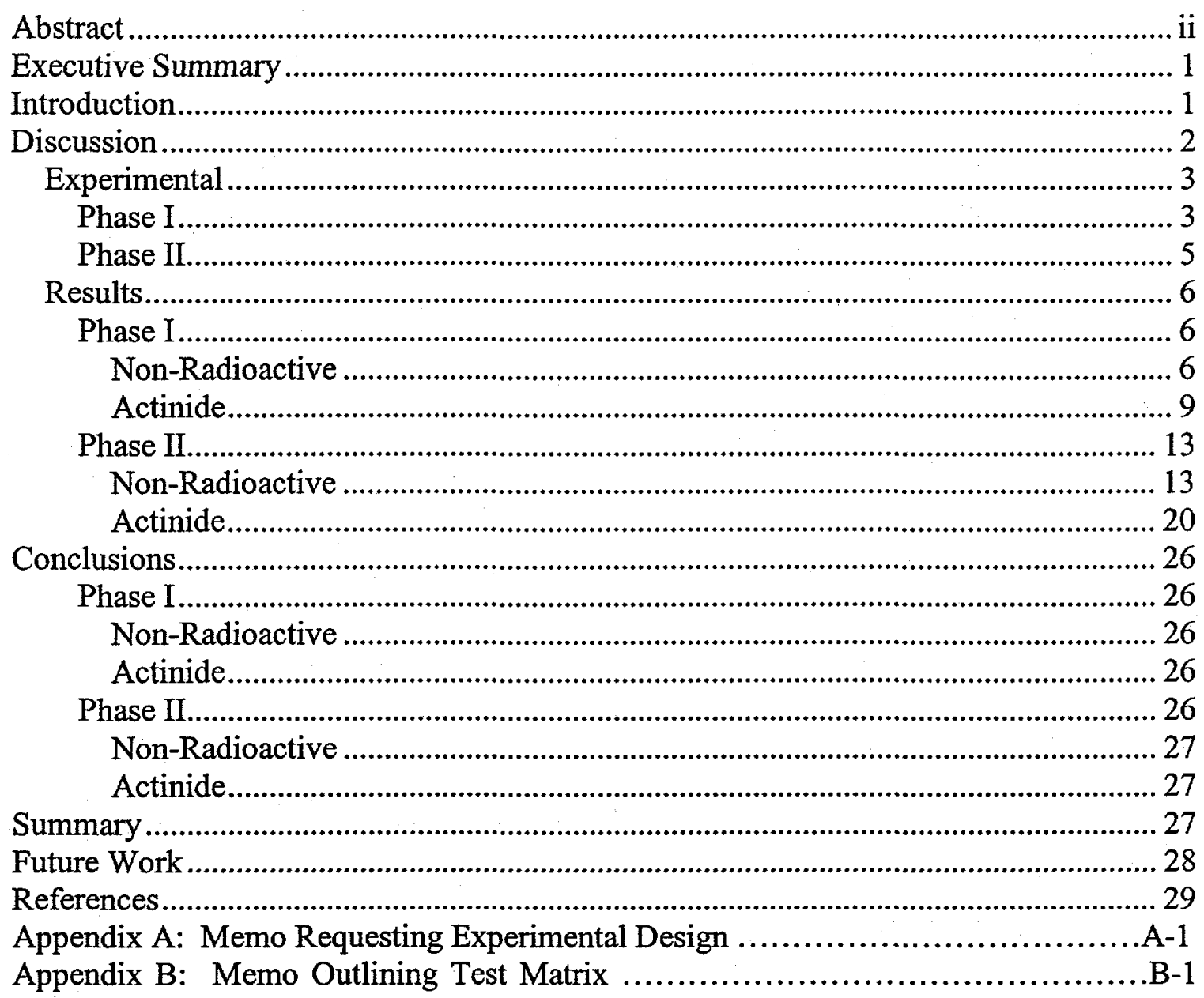


WSRC-TR-99-00479

Revision: 0

\section{List Of Tables}

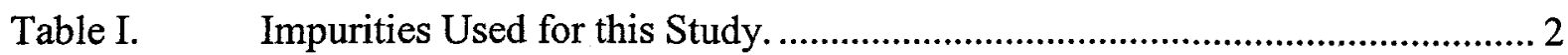

Table II. Base Compositions for the Volatile Impurity Study........................................... 4

Table III. Base Compositions in Weight Percent for the Phase I Tests.......................... 4

Table IV. Measured Density and Apparent Porosity of Non-Radioactive Pellets Made with Impurities. ...................................................................................... 7

Table V. Mineralogy of the Baseline Composition (A0/Ce/s) with Added Impurities. .. 7

Table VI. Mineralogy of the Baseline Composition (B3-7/s) with Added Impurities...... 8

Table VII. Mineralogy of the Baseline Composition (B3-8/s) with Added Impurities...... 9

Table VIII. Measured Density and Apparent Porosity of Uranium-Bearing Pellets Made with Impurities. ................................................................................. 10

Table X. Mineralogy of the A0/Th Composition with Impurities................................. 11

Table XI. Mineralogy of the B3-7 Composition with Impurities. ..................................... 11

Table XII. Mineralogy of the B3-8 Composition with Impurities. ................................. 12

Table XIII. Density of A0/Ce/s Pellets with 0.6 Moles Impurity Per Mole Plutonium (Ce).

Table XIV. Relative Intensities of Phases Detected in Impurity Matrix Pellets with 0.6 Moles Impurity per Mole Plutonium (Ce)..................................................... 15

Table XV. Density of A0/Ce/s Pellets with 0.8 Moles Impurity Per Mole Plutonium (Ce).

Table XVI. Relative Intensities of Phases Detected in Non-Radioactive Impurity Matrix Pellets with 0.8 Moles Impurity per Mole Plutonium (Ce)................... 18

Table XVII. Archimedes Density of the Large Impurity Pellets....................................... 20

Table XVIII. Density of A0/Ce Pellets with 0.8 Moles Impurity Per Mole Plutonium (Ce).

Table XIX. Relative Intensities of Phases Detected in Actinide Impurity Matrix Pellets with 0.8 Moles Impurity per Mole Plutonium (Ce)........................................ 22

Table XX. Model Parameters for Apparent Porosity Ranked by Significance. ................ 24

Table XXI. Model Parameters for Brannerite, Rutile and Zirconolite Ranked by Significance.............................................................................................. 24

Table XXII. Average Bulk Density and Percent Shrinkage for Plutonium Bearing Impurity Pellets. 
WSRC-TR-99-00479

Revision: 0

\section{Executive Summary}

The primary goal for the impurity tests performed at SRS was to determine the maximum level of volatile impurities that can be accommodated into the ceramic form without significantly affecting product mineralogy or reducing product density. The chemical durability of the ceramic is dependent upon the durability and amount of the phases that make up the form. The apparent porosity determines the true surface area of the form and may influence the durability. Volatiles expected in the $\mathrm{Pu}$ feeds can be classified into three basic categories:

- $\quad$ Oxides (e.g., $\mathrm{PbO}, \mathrm{WO}_{3}$, and $\mathrm{ZnO}$ )

- Chlorides (e.g., $\mathrm{NaCl}, \mathrm{KCl}$, and $\mathrm{CaCl}_{2}$ )

- $\quad$ Fluorides (e.g., $\mathrm{CaF}_{2}$ and $\mathrm{MgF}_{2}$ )

The mineralogy of the pyrochlore based ceramic form is tolerant of a broad range of impurities. Fifteen volatile impurities were added individually and concurrently to the form composition. In the actinide compositions that were made with cerium as a surrogate for plutonium, there was no x-ray diffraction evidence of objectionable quantities of secondary phases. Densification, as measured by apparent porosity, was significantly affected by eleven of the fifteen impurities. Sodium chloride was the only compound to significantly decrease the porosity of the ceramic. Additions of $\mathrm{MgCl}_{2}, \mathrm{ZnCl}_{2}, \mathrm{MgF}_{2}$ and $\mathrm{CaF}_{2}$ had no discernible effect on the density of the form. The apparent porosity of the ceramic form is somewhat sensitive to multiple impurity additions. Several two-factor interactions were significant in either increasing or decreasing the apparent porosity of the ceramic. However, there was not enough data collected for definitive conclusions. The lack of a simple "cause and effect" may be due to the complexity (fifteen impurities in each composition) of the system being studied. In this study, apparent porosity is used as an indication of sintering effects. The apparent porosity is correlated to the shrinkage associated with sintering and will be reflected in the final dimensions of the ceramic form.

\section{Introduction}

The focus of the Product Control Model (PCM) development task is to develop the methodology used to ensure that the ceramic fabrication process will yield an acceptable product as specified in Reference 1 .

In FY99, a series of samples were made to further understand the effects of impurities on the characteristics of the ceramic product. These samples were tailored to determine partitioning coefficients of the impurities in the major phases and to determine cumulative or combined effects of impurities on stabilizing major, minor, and trace phases in the ceramic.

The impurity tests were divided into three basic areas:

- Demonstration of impurity equivalence or near equivalence,

- Saturation of impurities to form minor constituent phases, and

- Determination of the effect of volatile impurities. 
The primary goal for the impurity tests performed at SRS was to determine the maximum level of volatile impurities that can be accommodated into the ceramic form without significantly affecting product properties or reducing product density. The chemical durability of the ceramic is dependent upon the durability and amount of the phases that make up the form. The apparent porosity determines the true surface area of the form and may influence the durability. Volatiles were separated into three categories based on anticipated $\mathrm{Pu}$ feed stream compositions:

- Oxides (e.g., $\mathrm{PbO}, \mathrm{WO}_{3}$, and $\mathrm{ZnO}$ )

- Chlorides (e.g., $\mathrm{NaCl}, \mathrm{KCl}$, and $\mathrm{CaCl}_{2}$ )

- Fluorides (e.g., $\mathrm{CaF}_{2}$ and $\mathrm{MgF}_{2}$ )

Ceramic pellets using the baseline (A0) composition, as well as other compositions, were produced with predetermined levels of impurities expected in the plutonium feed stream. The pellets were evaluated to determine the effects of the volatile impurities on the mineralogy and apparent porosity of the waste form. The volatility subtask was conducted in two major phases. ${ }^{2}$ The first phase evaluated each impurity separately in the waste form. The second phase implemented an experimental design to determine the effect of multiple impurities and the potential interactions on the properties of the waste form.

\section{Discussion}

Phase I of the volatile species subtask was planned to evaluate the effect of each impurity on the properties (apparent porosity and phase assemblage) of the ceramic form. The category of volatile impurities has been further divided into the three categories of oxides, chlorides and fluorides. Table I is the impurities used for this study and the materials used to represent them. The samples, prepared using cerium as a surrogate for both uranium and plutonium, were performed as scoping tests to determine the best methodology for sample preparation, handling and analysis. After the experimental parameters were defined, the tests were repeated for each composition using uranium.

Table I. Impurities Used for this Study.

\begin{tabular}{|c|c|c|c|c|c|}
\hline \multicolumn{2}{|r|}{ Oxides } & \multicolumn{2}{|c|}{ Chlorides } & \multicolumn{2}{|c|}{ Fluorides } \\
\hline Impurity & Source & Impurity & Source & Impurity & Source \\
\hline $\mathrm{B}_{2} \mathrm{O}_{3}$ & $\mathrm{H}_{3} \mathrm{BO}_{3}$ & $\mathrm{MgCl}_{2}$ & $\mathrm{MgCl}_{2} \bullet 6 \mathrm{H}_{2} \mathrm{O}$ & $\mathrm{CaF}_{2}$ & $\mathrm{CaF}_{2}$ \\
\hline $\mathrm{MoO}_{3}$ & $\mathrm{MoO}_{3}$ & $\mathrm{NaCl}$ & $\mathrm{NaCl}$ & $\overline{\mathrm{MgF}_{2}}$ & $\overline{\mathrm{MgF}_{2}}$ \\
\hline $\mathrm{ZnO}$ & $\mathrm{ZnO}$ & $\mathrm{CaCl}_{2}$ & $\overline{\mathrm{CaCl}_{2} \bullet 2 \mathrm{H}_{2} \mathrm{O}}$ & & \\
\hline$\overline{\mathrm{WO}_{3}}$ & $\overline{\mathrm{WO}_{3}}$ & $\overline{\mathrm{ZnCl}_{2}}$ & $\mathrm{ZnCl}_{2}$ & & \\
\hline $\mathrm{PbO}$ & $\mathrm{PbO}$ & $\mathrm{KCl}$ & $\mathrm{KCl}$ & & \\
\hline $\mathrm{Na}_{2} \mathrm{O}$ & $\mathrm{NaOH}$ or $\mathrm{Na}_{2} \mathrm{CO}_{3}$ & & & & \\
\hline $\mathrm{K}_{2} \mathrm{O}$ & $\mathrm{KOH}$ or $\mathrm{K}_{2} \mathrm{CO}_{3}$ & & & & \\
\hline $\mathrm{P}_{2} \mathrm{O}_{5}$ & $\mathrm{P}_{2} \mathrm{O}_{5}$ & & & & \\
\hline
\end{tabular}

In these tests, cerium was only used as a surrogate for plutonium. Uranium tests are necessary because some of the processing difficulties and subsequent poor properties may be attributed to cerium behavior (e.g. change in oxidation state) during sintering. However, the 
deleterious effects of cerium as a surrogate for plutonium have not been quantified and cerium-based testing provides other useful data, and the testing is significantly more cost effective than uranium.

Phase II consisted of developing an experimental design that considered the appearance of more than one impurity being present and evaluated the influence of potential interactions among the impurities on the mineralogy and the apparent porosity of the ceramic form. The materials handling and processing aspects of the experiments were previously determined in Phase I. Additional Phase II work included production of a select subset of large A0/Ce/s pellets. These pellets were made to determine the effect of scale on the impurity effects and production of the most problematic impurity compositions as determined by the $\mathrm{A} 0 / \mathrm{Ce} / \mathrm{U}$ impurity matrix. Finally, a few select compositions were fabricated with plutonium and uranium to correlate the surrogate testing with actual actinide chemistries.

The Quality Assurance Program followed in this study is detailed elsewhere ${ }^{2}$. Phase I experiments were performed using good laboratory practices (e.g., well documented lab notebooks, calibrated equipment, and qualified personnel. Phase II experiments were conducted in accordance with DOE/RW-0333P Quality Assurance Requirements.

\section{Experimental}

\section{Phase I}

The compositions and the amounts of impurities examined were set based on the history of the plutonium feedstock ${ }^{1}$. Table II lists the three compositions that were used in Phase I of the impurity study. $\mathrm{A} 0$ is the baseline formulation and targets the preferred composition. The "Ce" designation indicates a ceria substitution for plutonium oxide on a molar basis. The A0 baseline composition with uranium was also produced using thorium as the surrogate for plutonium. This was done to eliminate any oxidation/reduction effects that may be introduced by cerium. B3-7 is a compositional extreme that targets a $50 \% / 50 \%$ pyrochlore/zirconolite phase assemblage and uses ceria as a surrogate for plutonium oxide on a molar basis. B3-8 is a compositional extreme that targets a $50 \% / 50 \%$ pyrochlore/brannerite phase assemblage and, like B3-7, uses ceria as a surrogate for plutonium. These compositions were the base compositions to which the impurities were added. Since the precursor materials are premixed and metered in based on the plutonium concentration of the feed, It is unlikely that the composition of the ceramic form will vary substantially from the projected baseline composition.

It is expected that the range of occurrence of any of the impurity materials will range from 0 -0.6 moles of impurity per mole of plutonium. This range of occurrence was used as the basis for adding 0.6 moles impurity per mole plutonium for this study. For the first part of Phase I, cerium was also used as a surrogate for uranium. These samples were identified by an "/s" appended to the label. 
Table II. Base Compositions for the Volatile Impurity Study.

\begin{tabular}{|l|c|c|c|}
\hline \multirow{2}{*}{$\begin{array}{l}\text { Mrojected } \\
\text { Rineralogy }\end{array}$} & \multicolumn{3}{|c|}{ Composition in Mol Percent } \\
\cline { 2 - 4 } & A0/Ce & B3-7 & B3-8 \\
\hline $\mathrm{CaO}$ & 21.37 & $\begin{array}{c}\text { Zirconolite/ } \\
\text { Pyrochlore }\end{array}$ & $\begin{array}{c}\text { Brannerite/ } \\
\text { Pyrochlore }\end{array}$ \\
\hline $\mathrm{TiO}_{2}$ & 54.05 & 51.35 & 13.29 \\
\hline $\mathrm{HfO}_{2}$ & 6.09 & 13.94 & 59.13 \\
\hline $\mathrm{Gd}_{2} \mathrm{O}_{3}$ & 2.64 & 2.21 & 6.02 \\
\hline $\mathrm{UO}_{2}$ & 10.56 & 6.91 & 2.23 \\
\hline $\mathrm{CeO}_{2}\left(\mathrm{PuO}_{2}\right)$ & 5.28 & 4.28 & 13.22 \\
\hline $\mathrm{Al}_{2} \mathrm{O}_{3}$ & 0.00 & 1.35 & 6.11 \\
\hline Total & 99.99 & 100.00 & 0.00 \\
\hline
\end{tabular}

The base powders were produced by weighing out the prescribed amounts of batch material to produce the molar compositions in Table II. Table III is the weight percent of the materials for each of the three compositions. The batched powders (precursors $+\mathrm{CeO}_{2}$ ) were poured into a polypropylene bottle that was filled halfway with one-quarter inch cylindrical calcium-stabilized zirconia grinding media (Ca-PSZ). Enough water was added to the powder/Ca-PSZ media to produce a thin slurry. The slurry was milled $\sim 20 \mathrm{hr}$ on a roller mill. After milling, the slurry was poured through a coarse screen into a glass beaker to separate the slurry from the grinding media. Any remaining slurry was rinsed from the media into the beaker with distilled water. The slurry then was dried until no moisture was retained. The dried cake was crushed and then forced through a 40 mesh $(420 \mu \mathrm{m})$ sieve. The $<420 \mu \mathrm{m}$ powder was placed in a shallow alumina tray and calcined at $750^{\circ} \mathrm{C}$ for $1 \mathrm{hr}$. After cooling, the calcined powder was stored for future use*.

Table III. Base Compositions in Weight Percent for the Phase I Tests.

\begin{tabular}{|c|c|c|c|}
\hline Material & $\mathrm{A} 0 / \mathrm{s}$ & $\mathrm{B} 3-7 \mathrm{~s}$ & $\mathrm{~B} 3-8 \mathrm{~s}$ \\
\hline $\mathrm{Ca}(\mathrm{OH})_{2}$ & 15.10 & 13.42 & 9.06 \\
\hline $\mathrm{TiO}_{2}(\mathrm{~A})$ & 41.19 & 37.23 & 43.45 \\
\hline $\mathrm{HfO}_{2}$ & 12.24 & 26.63 & 11.65 \\
\hline $\mathrm{Gd}_{2} \mathrm{O}_{3}$ & 9.13 & 7.26 & 7.42 \\
\hline $\mathrm{CeO}_{2}$ & 26.02 & 17.48 & 30.61 \\
\hline $\mathrm{Al}_{2} \mathrm{O}_{3}$ & 0.00 & 1.25 & 0.00 \\
\hline Total & 103.68 & 103.26 & 102.20 \\
\hline
\end{tabular}

(A) Anatase form of titanium dioxide.

\begin{tabular}{|c|c|c|c|c|}
\hline Material & $\mathrm{A} 0 / \mathrm{Ce}$ & $\mathrm{A} 0 / \mathrm{Th}$ & B3-7 & B3-8 \\
\hline $\mathrm{Ca}(\mathrm{OH})_{2}$ & 13.74 & 13.19 & 12.64 & 8.09 \\
\hline $\mathrm{TiO}_{2}(\mathrm{~A})$ & 37.49 & 35.97 & 35.07 & 38.83 \\
\hline $\mathrm{HfO}_{2}$ & 11.14 & 10.69 & 25.09 & 10.41 \\
\hline $\mathrm{Gd}_{2} \mathrm{O}_{3}$ & 8.31 & 7.98 & 6.84 & 6.63 \\
\hline $\mathrm{CeO}_{2}$ & 7.89 & 0.00 & 6.30 & 8.65 \\
\hline $\mathrm{Al}_{2} \mathrm{O}_{3}$ & 0.00 & 0.00 & 1.17 & 0.00 \\
\hline $\mathrm{ThO}_{2}$ & 0.00 & 11.62 & 0.00 & 0.00 \\
\hline $\mathrm{UO}_{2}$ & 24.77 & 23.76 & 15.96 & 29.35 \\
\hline Total & 103.34 & 103.21 & 103.07 & 101.96 \\
\hline
\end{tabular}

For each of the three base compositions, three pellets for each of the fifteen impurities added individually in each composition were pressed. Three pellets were also made with no impurities added to provide a reference apparent porosity and x-ray diffraction pattern for

\footnotetext{
* The significant variation from the baseline process was necessary to intimately mix the $\mathrm{CeO}_{2}$ with the precursors as use of an attritor mill was not practical for the batch size used.
} 
WSRC-TR-99-00479

Revision: 0

each base composition. This resulted in 48 pellets for each of the three base compositions ( 3 pellets $\mathrm{x}(15$ impurities +1 base $)$ ).

To make three pellets with a single impurity, 6.5 grams of the base powder was weighed out and set aside. The amount of the impurity was calculated from the mole percent ceria as plutonium oxide in Table I ( 0.6 moles impurity per mole ceria). A small amount of the base powder was co-ground with the impurity using an agate mortar and pestle. The mixed/ground powders were added back to the remnants of the 6.5 grams of base powder and mixed on a roller mill for approximately ten minutes. The mixed powder was divided and used to press three pellets ( $\sim 2$ grams each). The pellets were sintered by heating at $5^{\circ} \mathrm{C} / \mathrm{min}$ to $1350^{\circ} \mathrm{C}$ and holding for $4 \mathrm{hr}$ in an air atmosphere. An yttria stabilized zirconia foam board was used as the setter material for sintering. The apparent porosity was determined for all pellets using the Archimedes method*. The mineralogy was determined for one pellet from each impurity composition using $\mathrm{x}$-ray diffraction. In these ceramics, $\mathrm{x}$-ray diffraction can detect phases that are present in quantities as low as three volume percent. For all phases of interest, only the actinide oxide $\left(\mathrm{Pu}, \mathrm{UO}_{2}\right)$ is a concern near the detection limit. Pellets that were not consumed for XRD analysis were archived for future use.

\section{Phase II}

Baseline powders for Phase II were prepared in the same manner as the powders used in Phase I. In Phase II, however, only the A0/Ce/s (Ce-Ce) and A0/Ce (Ce-U) compositions were used for impurity additions. A request was issued to the Savannah River Technology Center (SRTC) Statistical Consulting Section (SCS) for an experimental design that would evaluate the influence of the impurities on the density (porosity) and the mineralogy of the baseline compositions, Appendix A. The SCS document "Test Matrix for Volatile Impurity Study in Support of the Pu Immobilization Task (U)", Appendix B, provided a compositional matrix. In addition to the 45 compositions specified by the SCS document, the centroid composition was added in triplicate. The centroid composition was $0.6 / 15 \mathrm{~mol}$ of each of the fifteen impurities. One of these replicates was batched as a triple size batch. This resulted in 48 impurity compositions numbered $0-48$. The reference composition with no impurities was number zero. The centroid replicates became composition numbers 16 (triple batch), 32 and 48. These additional compositions served several purposes. First, the production of a centroid composition with each sintering batch could quantify the variations associated with batching chemicals. Second, pellets from the large centroid batch could quantify the variations associated with pressing and sintering. Lastly, the centroid composition adds another data point for analysis. These tests were repeated using 0.8 moles of impurity per mole of plutonium (Ce). The relative amounts of the impurities remained the same and the subsequent pellets were numbered 49-96. Only the 0.8 moles impurities per mole plutonium (Ce) pellets were produced with the $\mathrm{A} 0 / \mathrm{Ce} / \mathrm{U}$ base composition. To maintain consistency, the pellets made with $\mathrm{A} 0 / \mathrm{Ce} / \mathrm{U}$ were also numbered 49-96.

\footnotetext{
* ASTM C 373-88 Standard Test Method for Water Absorption, Bulk Density, Apparent Porosity, and Apparent Specific Gravity of Fired Whiteware Products adapted to measure small samples.
} 
In addition to the pellets produced above, large $\mathrm{A} 0 / \mathrm{Ce} / \mathrm{s}$ pellets were produced from three of the potentially most problematic compositions as determined by apparent porosity. Impurity compositions with 0.8 moles impurities per mole plutonium (Ce), Impurity-57, -84 , and -89 (TBE compositions $-9,-34$, and -39 ) were each admixed to $115 \mathrm{~g}$ of the $\mathrm{A} 0 / \mathrm{ce} / \mathrm{s}$ baseline. Each composition resulted in one 2.125 in diameter green pellet. The pellets were sintered as all the previous pellets and density and mineralogy were determined.

The impurity compositions were batched and added to the base powders in the same manner as in Phase I. The exception to this method was for the two compositions that were produced in the glovebox using plutonium. In this case, the precursor materials were wet milled with the impurities. The precursor/impurity mix was not calcined. This was done to eliminate the chance that part or all of the impurities would volatilize during the calcination step. The product was inserted into the glovebox and the $\mathrm{UO}_{2}$ and $\mathrm{PuO}_{2}$ were added. The $\mathrm{UO}_{2}$ was not calcined before use. The apparent porosity and mineralogy of small pellets are not sensitive to the initial oxidation state of the uranium ${ }^{3}$. The resulting batch was milled for approximately eight hours. The slurry was screened to remove the grinding media and dried on a hot plate. The resulting cake was crushed and forced through a 40 mesh sieve. The powder was pressed into pellets and sintered as before. Density was measured geometrically and one pellet was submitted for XRD analysis. Relative phase abundance was determined by comparing the intensity of the primary peak for each of the phases to that of the intensity of the main pyrochlore peak. The main peak of the zirconolite phase is masked by the main pyrochlore peak. Therefore, the abundance of zirconolite was determined by comparing the intensity of a secondary peak at $31.2^{\circ} 2 \theta$ to a pyrochlore peak of similar expected intensity at $30.5^{\circ} 2 \theta$.

\section{Results}

\section{Phase I}

\section{Non-Radioactive}

Archimedes density was performed on all of the non-radioactive samples. Table IV is the average density and apparent porosity of three pellets for each composition. The apparent porosity is a better tool for comparison because of the different densities of the impurities but and because the phase assemblage and the quantity of each phase vary for all of the impurities. Most of the impurity pellets made with the A0/Ce/s composition had apparent porosities similar to that of the reference pellets. Additions of either $\mathrm{K}_{2} \mathrm{O}$ or $\mathrm{P}_{2} \mathrm{O}_{5}$ slightly increased the apparent porosity. Pellets made with $\mathrm{MoO}_{3}$ and $\mathrm{WO}_{3}$ using the $\mathrm{B} 3-7 \mathrm{~s}$ base composition produced pellets with an average apparent porosity of $25.7 \%$ and $11.23 \%$ respectively. The amount of impurity was then reduced to 0.3 and 0.4 moles impurity per mole plutonium for $\mathrm{MoO}_{3}$ and 0.4 and 0.5 moles impurity per mole plutonium for $\mathrm{WO}_{3}$. Following the decrease in impurity concentration, the apparent porosity for these pellets decreased to less than ten percent. Pellets made with $\mathrm{PbO}$ and $\mathrm{P}_{2} \mathrm{O}_{5}$ had apparent porosities noticeably greater than the reference pellets for the B3-8s composition. 
Table IV. Measured Density and Apparent Porosity of Non-Radioactive Pellets Made with Impurities.

\begin{tabular}{|c|c|c|c|c|c|c|}
\hline Baseline & \multicolumn{2}{|c|}{$\mathrm{A} 0 / \mathrm{Ce} / \mathrm{s}$} & \multicolumn{2}{|c|}{ B3-7s } & \multicolumn{2}{|c|}{ B3-8s } \\
\hline $\begin{array}{c}0.6 \mathrm{~mol} / \\
\mathrm{mol} \mathrm{Pu}\end{array}$ & $\begin{array}{l}\text { Apparent } \\
\text { Porosity }\end{array}$ & $\begin{array}{l}\text { Density } \\
\left(\mathrm{g} / \mathrm{cm}^{3}\right)\end{array}$ & $\begin{array}{l}\text { Apparent } \\
\text { Porosity }\end{array}$ & $\begin{array}{l}\text { Density } \\
\left(\mathrm{g} / \mathrm{cm}^{3}\right)\end{array}$ & $\begin{array}{c}\text { Apparent } \\
\text { Porosity }\end{array}$ & $\begin{array}{l}\text { Density } \\
\left(\mathrm{g} / \mathrm{cm}^{3}\right)\end{array}$ \\
\hline Reference & $1.29 \%$ & 4.965 & $2.53 \%$ & 4.990 & $1.46 \%$ & 5.069 \\
\hline $\mathrm{B}_{2} \mathrm{O}_{3}$ & $1.77 \%$ & 4.300 & $5.54 \%$ & 4.563 & $1.78 \%$ & 4.205 \\
\hline $\mathrm{CaCl}_{2}$ & $0.76 \%$ & 4.962 & $9.74 \%$ & 4.640 & $0.45 \%$ & 5.056 \\
\hline $\mathrm{CaF}_{2}$ & $2.00 \%$ & 4.861 & $3.30 \%$ & 4.959 & $2.64 \%$ & 4.903 \\
\hline $\mathrm{KCl}$ & $2.18 \%$ & 4.798 & $9.31 \%$ & 4.719 & $2.08 \%$ & 4.957 \\
\hline $\mathrm{MgCl}_{2}$ & $0.96 \%$ & 4.955 & $1.44 \%$ & 5.120 & $0.55 \%$ & 5.053 \\
\hline $\mathrm{MgF}_{2}$ & $1.55 \%$ & 4.871 & $2.55 \%$ & 4.991 & $1.86 \%$ & 4.911 \\
\hline $\mathrm{NaCl}$ & $1.30 \%$ & 4.892 & $1.94 \%$ & 4.933 & $0.86 \%$ & 4.956 \\
\hline $\mathrm{MoO}_{3}$ & $1.35 \%$ & 4.816 & $25.74 \%$ & 4.013 & $3.53 \%$ & 4.840 \\
\hline $\mathrm{WO}_{3}$ & $1.37 \%$ & 4.933 & $11.34 \%$ & 4.612 & $2.69 \%$ & 4.844 \\
\hline $\mathrm{ZnO}$ & $2.73 \%$ & 4.922 & $5.90 \%$ & 4.895 & $1.89 \%$ & 5.017 \\
\hline $\mathrm{PbO}$ & $1.76 \%$ & 4.875 & $4.44 \%$ & 5.043 & $5.98 \%$ & 4.820 \\
\hline $\mathrm{Na}_{2} \mathrm{CO}_{3}$ & $1.73 \%$ & 4.819 & $2.30 \%$ & 4.896 & $1.01 \%$ & 4.939 \\
\hline $\mathrm{K}_{2} \mathrm{CO}_{3}$ & $5.78 \%$ & 4.594 & $5.28 \%$ & 4.911 & $0.72 \%$ & 5.065 \\
\hline $\mathrm{P}_{2} \mathrm{O}_{5}$ & $5.52 \%$ & 4.500 & $1.77 \%$ & 4.917 & $11.65 \%$ & 4.152 \\
\hline $\mathrm{ZnCl}_{2}$ & $1.13 \%$ & 4.910 & $0.73 \%$ & 5.229 & $1.25 \%$ & 4.886 \\
\hline
\end{tabular}

A0/Ce/s. X-ray diffraction analysis was performed on one pellet from each of the impurity compositions. A pellet with no impurities also was analyzed to provide a reference. Table $\mathrm{V}$ is the phases determined by XRD and the relative abundance of each phase for the $\mathrm{A} 0 / \mathrm{Ce} / \mathrm{s}$ composition. The reference composition was determined to be primarily pyrochlore with trace quantities of perovskite and rutile. Additions of $\mathrm{MgCl}_{2}, \mathrm{MgF}_{2}, \mathrm{ZnO}, \mathrm{Na}_{2} \mathrm{O}, \mathrm{K}_{2} \mathrm{O}$, $\mathrm{P}_{2} \mathrm{O}_{5}$ or $\mathrm{ZnCl}_{2}$ resulted in the formation of additional phases. In the instance of a $\mathrm{Na}_{2} \mathrm{O}$ addition, abundant amounts of an unfavorable phase (perovskite) were formed. The formation of significant amounts of perovskite was not the case with a $\mathrm{NaCl}$ or a $\mathrm{K}_{2} \mathrm{O}$ addition as might be expected. In the $\mathrm{MoO}_{3}$ impurity sample, trace amounts of unreacted ceria were observed. The presence of ceria can be related to the unreacted or undissolved actinides that have been described as appearing in pellets made with plutonium and uranium ${ }^{1}$.

B3-7/s. Table VI shows the phases determined by XRD and the relative abundance of each phase for the B3-7s composition. The reference composition is primarily pyrochlore and zirconolite with trace quantities of perovskite and rutile. Additions of $\mathrm{MgCl}_{2}, \mathrm{MgF}_{2}$, $\mathrm{NaCl}, \mathrm{ZnO}, \mathrm{Na}_{2} \mathrm{O}, \mathrm{K}_{2} \mathrm{O}, \mathrm{P}_{2} \mathrm{O}_{5}$ or $\mathrm{ZnCl}_{2}$ resulted in the formation of additional phases. All of the additional phases formed were previously identified as a potential phase ${ }^{1}$. These additional phases appeared in amounts deemed acceptable ${ }^{1}$. 
Table V. Mineralogy of the Baseline Composition (A0/Ce/s) with Added Impurities.

\begin{tabular}{|c|c|c|c|c|c|}
\hline Target & Pyrochlore & Zirconolite & Perovskite & Rutile & Monazite \\
\hline Reference & Primary & -- & Trace & Trace & -- \\
\hline $\mathrm{B}_{2} \mathrm{O}_{3}$ & Primary & -- & -- & Minor & -- \\
\hline $\mathrm{CaCl}_{2}$ & Primary & -- & Minor & Trace & -- \\
\hline $\mathrm{CaF}_{2}$ & Primary & -- & Minor & -- & -- \\
\hline $\mathrm{KCl}$ & Primary & -- & Trace & Trace & -- \\
\hline $\mathrm{MgCl}_{2}$ & Primary & Trace & Minor & -- & -- \\
\hline $\mathrm{MgF}_{2}$ & Primary & Minor & Minor & -- & -- \\
\hline $\mathrm{NaCl}$ & Primary & -- & Minor & Trace & -- \\
\hline $\mathrm{MoO}_{3}$ & Primary & -- & -- & Minor & -- \\
\hline $\mathrm{WO}_{3}$ & Primary & -- & -- & Minor & -- \\
\hline $\mathrm{ZnO}$ & Primary & Minor & Minor & -- & -- \\
\hline $\mathrm{PbO}$ & Primary & -- & Minor & Trace & -- \\
\hline $\mathrm{Na}_{2} \mathrm{O}$ & Primary & Minor & Abundant & -- & -- \\
\hline $\mathrm{K}_{2} \mathrm{O}$ & Primary & Trace & -- & Trace & -- \\
\hline $\mathrm{P}_{2} \mathrm{O}_{5}$ & Primary & -- & -- & Common & Minor \\
\hline $\mathrm{ZnCl}_{2}$ & Primary & Minor & Trace & Trace & -- \\
\hline
\end{tabular}

Primary $>$ Abundant $>$ Common $>$ Minor $>$ Trace

Table VI. Mineralogy of the Baseline Composition (B3-7/s) with Added Impurities.

\begin{tabular}{|c|c|c|c|c|}
\hline Target & Pyrochlore & Zirconolite & Perovskite & Rutile \\
\hline Reference & Abundant & Abundant & -- & -- \\
\hline $\mathrm{B}_{2} \mathrm{O}_{3}$ & Abundant & Abundant & -- & - \\
\hline $\mathrm{CaCl}_{2}$ & Abundant & Abundant & -- & -- \\
\hline $\mathrm{CaF}_{2}$ & Abundant & Abundant & -- & -- \\
\hline $\mathrm{KCl}$ & Abundant & Abundant & -- & -- \\
\hline $\mathrm{MgCl}_{2}$ & Abundant & Abundant & Minor & -- \\
\hline $\mathrm{MgF}_{2}$ & Abundant & Abundant & Trace & -- \\
\hline $\mathrm{NaCl}$ & Abundant & Abundant & Minor & -- \\
\hline $\mathrm{MoO}_{3}$ & Abundant & Abundant & -- & -- \\
\hline $\mathrm{WO}_{3}$ & Abundant & Abundant & -- & -- \\
\hline $\mathrm{ZnO}$ & Abundant & Abundant & Minor & -- \\
\hline $\mathrm{PbO} \mathrm{A}$ & Abundant & Abundant & -- & -- \\
\hline $\mathrm{Na}_{2} \mathrm{O}$ & Abundant & Abundant & Abundant & -- \\
\hline $\mathrm{K}_{2} \mathrm{O}$ & Abundant & Abundant & Minor & Trace \\
\hline $\mathrm{P}_{2} \mathrm{O}_{5}$ & Abundant & Abundant & -- & Common \\
\hline $\mathrm{ZnCl}_{2}$ & Abundant & Abundant & Minor & -- \\
\hline
\end{tabular}

Primary $>$ Abundant $>$ Common $>$ Minor $>$ Trace

B3-8/s. Table VII is the phases determined by XRD and the relative abundance of each phase for the B3-8s composition. The reference composition is primarily pyrochlore and rutile. Additions of $\mathrm{ZnO}, \mathrm{Na}_{2} \mathrm{O}, \mathrm{P}_{2} \mathrm{O}_{5}$ or $\mathrm{ZnCl}_{2}$ resulted in the formation of additional phases. Measurable amounts of unreacted ceria were observed in the $\mathrm{B}_{2} \mathrm{O}_{3}, \mathrm{CaF}_{2}$, and $\mathrm{MoO}_{3}$ impurity samples. 
Table VII. Mineralogy of the Baseline Composition (B3-8/s) with Added Impurities.

\begin{tabular}{|c|c|c|c|c|c|}
\hline Target & Pyrochlore & Zirconolite & Perovskite & Rutile & Monazite \\
\hline Reference & Primary & -- & -- & Common & -- \\
\hline $\mathrm{B}_{2} \mathrm{O}_{3}$ & Primary & - & -- & Common & -- \\
\hline $\mathrm{CaCl}_{2}$ & Primary & -- & -- & Common & -- \\
\hline $\mathrm{CaF}_{2}$ & Primary & -- & -- & Common & -- \\
\hline $\mathrm{KCl}$ & Primary & -- & -- & Common & -- \\
\hline $\mathrm{MgCl}_{2}$ & Primary & - & -- & Common & -- \\
\hline $\mathrm{MgF}_{2}$ & Primary & -- & -- & Common & -- \\
\hline $\mathrm{NaCl}$ & Primary & - & -- & Common & -- \\
\hline $\mathrm{MoO}_{3}$ & Primary & -- & -- & Common & -- \\
\hline $\mathrm{WO}_{3}$ & Primary & -- & -- & Common & -- \\
\hline $\mathrm{ZnO}$ & Primary & Minor & -- & Common & -- \\
\hline $\mathrm{PbO}^{\mathrm{Na} O} \mathrm{O}$ & Primary & -- & -- & Common & -- \\
\hline $\mathrm{K}_{2} \mathrm{O}$ & Primary & -- & Common & Common & -- \\
\hline $\mathrm{P}_{2} \mathrm{O}_{5}$ & Primary & -- & -- & Minor & -- \\
\hline $\mathrm{ZnCl}_{2}$ & Primary & -- & -- & Common & Minor \\
\hline
\end{tabular}

Primary $>$ Abundant $>$ Common $>$ Minor $>$ Trace

\section{Actinide}

Archimedes density was performed on all of the samples. Table VIII is the apparent porosity of three pellets for each composition. The apparent porosity of impurity pellets made with the $\mathrm{A} 0 / \mathrm{Ce} / \mathrm{U}$ composition measurably increased with additions of $\mathrm{B}_{2} \mathrm{O}_{3}, \mathrm{KCl}, \mathrm{MoO}_{3}, \mathrm{WO}_{3}$, $\mathrm{PbO}, \mathrm{NaOH}$ and $\mathrm{P}_{2} \mathrm{O}_{5}$. Additions of $\mathrm{B}_{2} \mathrm{O}_{3}$ and $\mathrm{P}_{2} \mathrm{O}_{5}$ resulted in apparent porosities that were significantly higher than the other impurity pellets. The other impurities either did not effect, or caused only a small increase in the apparent porosity. A similar response to impurity additions was observed in pellets made with the $\mathrm{A} 0 / \mathrm{Th} / \mathrm{U}$ base composition. Only the $\mathrm{WO}_{3}$ and the $\mathrm{PbO}$ samples exhibited significant differences in apparent porosity. No further testing in this subtask will be performed using $\mathrm{ThO}_{2}$. In the pellets made with the $\mathrm{B} 3-7$ base composition, additions of $\mathrm{B}_{2} \mathrm{O}_{3}, \mathrm{MoO}_{3}$, and $\mathrm{P}_{2} \mathrm{O}_{5}$ measurably increased the apparent porosity of the pellets. $\mathrm{MoO}_{3}$ was the only impurity that increased the apparent porosity to a level greater than ten percent. The other impurities either did not effect, or caused only a small increase in the apparent porosity. The B3-8 composition was affected by a greater number of impurities than either of the $\mathrm{A} 0$ or the $\mathrm{B} 3-7$ compositions. Additions of $\mathrm{B}_{2} \mathrm{O}_{3}, \mathrm{CaF}_{2}, \mathrm{KCl}$, $\mathrm{NaCl}, \mathrm{MoO}_{3}, \mathrm{PbO}, \mathrm{NaOH}, \mathrm{KOH}$ and $\mathrm{ZnCl}_{2}$ measurably increased the apparent porosity. $\mathrm{B}_{2} \mathrm{O}_{3}, \mathrm{KCl}, \mathrm{NaCl}, \mathrm{MoO}_{3}, \mathrm{KOH}$ and $\mathrm{ZnCl}_{2}$ all caused the apparent porosity of the pellets to be greater than ten percent. The other impurities either did not effect, or caused only a small increase in the apparent porosity. After sintering, pellets made with $\mathrm{KCl}$ and $\mathrm{KOH}$ disintegrated overnight in air. There is no current explanation for this behavior. Future impurity studies will consider this potential phenomenon when evaluating pellets. 
WSRC-TR-99-00479

Revision: 0

Table VIII. Measured Density and Apparent Porosity of Uranium-Bearing Pellets Made with Impurities.

\begin{tabular}{|c|c|c|c|c|}
\hline Baseline & $\mathrm{A} 0 / \mathrm{Ce} / \mathrm{U}$ & $\mathrm{A} 0 / \mathrm{Th} / \mathrm{U}$ & $\mathrm{B} 3-7$ & $\mathrm{~B} 3-8$ \\
\hline $0.6 \mathrm{~mol} /$ & Apparent & Apparent & Apparent & Apparent \\
\hline Reference & $0.64 \%$ & $0.55 \%$ & $2.56 \%$ & $1.06 \%$ \\
\hline $\mathrm{B}_{2} \mathrm{O}_{3}$ & $15.20 \%$ & $10.99 \%$ & $5.67 \%$ & $12.19 \%$ \\
\hline $\mathrm{CaCl}_{2}$ & $2.11 \%$ & $1.85 \%$ & $0.42 \%$ & $5.07 \%$ \\
\hline $\mathrm{CaF}_{2}$ & $1.16 \%$ & $1.22 \%$ & $0.87 \%$ & $3.36 \%$ \\
\hline $\mathrm{KCl}$ & $6.20 \%$ & $4.31 \%$ & $1.79 \%$ & N/A* \\
\hline $\mathrm{MgCl}_{2}$ & $1.49 \%$ & $1.33 \%$ & $0.96 \%$ & $1.49 \%$ \\
\hline $\mathrm{MgF} 2$ & $1.15 \%$ & $2.05 \%$ & $2.44 \%$ & $1.94 \%$ \\
\hline $\mathrm{NaCl}_{2}$ & $0.63 \%$ & $0.86 \%$ & $1.72 \%$ & $10.35 \%$ \\
\hline $\mathrm{MoO}_{3}$ & $6.80 \%$ & $7.82 \%$ & $13.75 \%$ & $25.11 \%$ \\
\hline $\mathrm{WO}_{3}$ & $5.30 \%$ & $1.37 \%$ & $1.81 \%$ & $2.85 \%$ \\
\hline $\mathrm{ZnO}$ & $1.46 \%$ & $0.78 \%$ & $2.62 \%$ & $0.94 \%$ \\
\hline $\mathrm{PbO}$ & $7.83 \%$ & $2.08 \%$ & $1.19 \%$ & $9.36 \%$ \\
\hline $\mathrm{Na}_{2} \mathrm{CO}_{3}$ & $5.92 \%$ & $1.27 \%$ & $0.98 \%$ & $6.14 \%$ \\
\hline $\mathrm{K}_{2} \mathrm{CO}_{3}$ & $2.62 \%$ & $5.09 \%$ & $1.74 \%$ & N/A* \\
\hline $\mathrm{P}_{2} \mathrm{O}_{5}$ & $11.46 \%$ & $11.43 \%$ & $7.21 \%$ & $1.81 \%$ \\
\hline $\mathrm{ZnCl}_{2}$ & $0.77 \%$ & $0.57 \%$ & $0.75 \%$ & $14.16 \%$ \\
\hline
\end{tabular}

* Pellets fragmented after sintering.

A0/Ce. Table IX is the phases determined by XRD and the relative abundance of each phase. The reference composition is primarily pyrochlore with large quantities of brannerite. Additions of $\mathrm{MgCl}_{2}, \mathrm{MgF}_{2}, \mathrm{ZnO}, \mathrm{Na}_{2} \mathrm{O}, \mathrm{K}_{2} \mathrm{O}$ or $\mathrm{P}_{2} \mathrm{O}_{5}$ resulted in the formation of additional phases. However, all of the phases formed were in the acceptable range of abundance from Reference 1.

Table IX. Mineralogy of the A0/Ce Composition with Impurities.

\begin{tabular}{|c|c|c|c|c|c|c|}
\hline Target & Pyrochlore & Brannerite & Zirconolite & Perovskite & Rutile & Monazite \\
\hline Reference & Primary & Abundant & -- & -- & -- & -- \\
\hline $\mathrm{B}_{2} \mathrm{O}_{3}$ & Primary & Common & -- & -- & -- & -- \\
\hline $\mathrm{CaCl}_{2}$ & Primary & Common & -- & -- & -- & -- \\
\hline $\mathrm{CaF}_{2}$ & Primary & Common & -- & -- & -- & -- \\
\hline $\mathrm{KCl}$ & Primary & Common & -- & -- & -- & -- \\
\hline $\mathrm{MgCl}_{2}$ & Primary & Common & Minor & -- & -- & -- \\
\hline $\mathrm{MgF}_{2}$ & Primary & Common & Minor & -- & -- & -- \\
\hline $\mathrm{NaCl}$ & Primary & Common & -- & -- & -- & -- \\
\hline $\mathrm{MoO}_{3}$ & Primary & Abundant & -- & -- & -- & -- \\
\hline $\mathrm{WO}_{3}$ & Primary & Abundant & -- & - & -- & -- \\
\hline $\mathrm{ZnO}$ & Primary & Abundant & & Trace & Common & \\
\hline $\mathrm{PbO}$ & Primary & Abundant & -- & -- & -- & -- \\
\hline $\mathrm{Na}_{2} \mathrm{O}$ & Primary & Common & -- & -- & Common & -- \\
\hline $\mathrm{K}_{2} \mathrm{O}$ & Primary & Trace & -- & -- & Common & -- \\
\hline $\mathrm{P}_{2} \mathrm{O}_{5}$ & Primary & Abundant & -- & -- & -- & Minor \\
\hline $\mathrm{ZnCl}_{2}$ & Primary & Abundant & -- & -- & -- & -- \\
\hline
\end{tabular}

Primary $>$ Abundant $>$ Common $>$ Minor $>$ Trace 
A0/Th. Table $\mathrm{X}$ is the phases determined by XRD and the relative abundance of each phase. The reference composition is primarily pyrochlore with significant quantities of brannerite. Additions of $\mathrm{MgCl}_{2}, \mathrm{ZnO}, \mathrm{Na}_{2} \mathrm{O}, \mathrm{K}_{2} \mathrm{O}$ or $\mathrm{ZnCl}_{2}$ resulted in the formation of additional phases. However, all of the phases formed were in the acceptable range of abundance from Reference 1. As with the apparent porosity, the mineralogy of the impurity samples made with thorium as the plutonium surrogate behave similarly to the samples made with cerium as the plutonium surrogate.

Table X. Mineralogy of the A0/Th Composition with Impurities.

\begin{tabular}{|c|c|c|c|c|c|}
\hline Target & Pyrochlore & Brannerite & Zirconolite & Rutile & Thorianite \\
\hline Reference & Primary & Common & -- & -- & -- \\
\hline $\mathrm{B}_{2} \mathrm{O}_{3}$ & Primary & Common & -- & -- & -- \\
\hline $\mathrm{CaCl}_{2}$ & Primary & Common & -- & -- & -- \\
\hline $\mathrm{CaF}_{2}$ & Primary & Common & -- & - & -- \\
\hline $\mathrm{KCl}$ & Primary & Common & -- & -- & -- \\
\hline $\mathrm{MgCl}_{2}$ & Primary & Common & Minor & -- & -- \\
\hline $\mathrm{MgF}_{2}$ & Primary & Common & -- & - & -- \\
\hline $\mathrm{NaCl}$ & Primary & Common & -- & -- & -- \\
\hline $\mathrm{MoO}_{3}$ & Primary & Common & -- & -- & -- \\
\hline $\mathrm{WO}_{3}$ & Primary & Common & - & - & -- \\
\hline $\mathrm{ZnO}^{\mathrm{PbO}}$ & Primary & Common & Common & Common & Trace \\
\hline $\mathrm{Na}_{2} \mathrm{O}$ & Primary & Common & -- & -- & -- \\
\hline $\mathrm{K}_{2} \mathrm{O}$ & Primary & Minor & -- & Minor & - \\
\hline $\mathrm{P}_{2} \mathrm{O}_{5}$ & Primary & Common & -- & Trace & -- \\
\hline $\mathrm{ZnCl}_{2}$ & Primary & Common & Minor & - & Trace \\
\hline
\end{tabular}

Primary $>$ Abundant $>$ Common $>$ Minor $>$ Trace

B3-7. Table XI is the phases determined by XRD and the relative abundance of each phase. This composition was designed to provide equal amounts of pyrochlore and zirconolite. In the reference composition, the secondary peak used to detect zirconolite in the presence of pyrochlore is of a relatively low intensity. This indicated that pyrochlore is formed preferentially over zirconolite when cerium is substituted for plutonium. Additions of either $\mathrm{B}_{2} \mathrm{O}_{3}$ or $\mathrm{P}_{2} \mathrm{O}_{5}$ resulted in the suppression of the zirconolite phase. The presence of $\mathrm{MoO}_{3}, \mathrm{WO}_{3}, \mathrm{ZnO}, \mathrm{PbO}$ and $\mathrm{P}_{2} \mathrm{O}_{5}$ induced the formation of measurable quantities of brannerite. However, all of the phases formed were in the acceptable range of abundance from Reference 1.

B3-8. Table XII is the phases determined by XRD and the relative abundance of each phase. Pellets made with the reference composition (no impurities) were mostly pyrochlore with significant amounts of brannerite. Trace amounts of perovskite were also detected in the reference pellets. Additions of $\mathrm{CaCl}_{2}, \mathrm{CaF}_{2}, \mathrm{NaCl}, \mathrm{NaOH}$, and $\mathrm{KOH}$ resulted in the elimination of the brannerite phase. As with all of the previous impurities and base compositions, all of the phases formed were again in the acceptable range of abundance from Reference 1. 
Table XI. Mineralogy of the B3-7 Composition with Impurities.

\begin{tabular}{|c|c|c|c|c|}
\hline Target & Pyrochlore & Brannerite & Zirconolite & Rutile \\
\hline Reference & Primary & -- & Trace & Minor \\
\hline $\mathrm{B}_{2} \mathrm{O}_{3}$ & Primary & -- & -- & Minor \\
\hline $\mathrm{CaCl}_{2}$ & Primary & -- & Minor & Minor \\
\hline $\mathrm{CaF}_{2}$ & Primary & -- & Minor & Minor \\
\hline $\mathrm{KCl}$ & Primary & -- & Trace & Minor \\
\hline $\mathrm{MgCl}_{2}$ & Primary & -- & Minor & Minor \\
\hline $\mathrm{MgF}_{2}$ & Primary & -- & Minor & Minor \\
\hline $\mathrm{NaCl}$ & Primary & -- & Minor & Minor \\
\hline $\mathrm{MoO}_{3}$ & Primary & Common & Common & -- \\
\hline $\mathrm{WO}_{3}$ & Primary & Minor & Minor & -- \\
\hline $\mathrm{ZnO}$ & Primary & Minor & Common & -- \\
\hline $\mathrm{PbO}$ & Primary & Minor & Minor & Trace \\
\hline $\mathrm{Na}_{2} \mathrm{O}$ & Primary & -- & Common & Common \\
\hline $\mathrm{K}_{2} \mathrm{O}$ & Primary & -- & Trace & Minor \\
\hline $\mathrm{P}_{2} \mathrm{O}_{5}$ & Primary & Trace & -- & Common \\
\hline $\mathrm{ZnCl}_{2}$ & Primary & -- & Minor & Minor \\
\hline
\end{tabular}

Primary $>$ Abundant $>$ Common $>$ Minor $>$ Trace

Table XII. Mineralogy of the B3-8 Composition with Impurities.

\begin{tabular}{|c|c|c|c|}
\hline Target & Pyrochlore & Brannerite & Perovskite \\
\hline Reference & Primary & Common & Trace \\
\hline $\mathrm{B}_{2} \mathrm{O}_{3}$ & Primary & Common & Trace \\
\hline $\mathrm{CaCl}_{2}$ & Primary & -- & Trace \\
\hline $\mathrm{CaF}_{2}$ & Primary & -- & Trace \\
\hline $\mathrm{KCl}$ & Primary & Common & Trace \\
\hline $\mathrm{MgCl}_{2}$ & Primary & Common & Minor \\
\hline $\mathrm{MgF}_{2}$ & Primary & Common & Minor \\
\hline $\mathrm{NaCl}$ & Primary & -- & Trace \\
\hline $\mathrm{MoO}_{3}$ & Primary & Common & Trace \\
\hline $\mathrm{WO}_{3}$ & Primary & Common & Trace \\
\hline $\mathrm{ZnO} \mathrm{Pb}$ & Primary & Common & Minor \\
\hline $\mathrm{PbO}$ & Primary & Common & Trace \\
\hline $\mathrm{Na}_{2} \mathrm{O}$ & Primary & -- & Trace \\
\hline $\mathrm{K}_{2} \mathrm{O}$ & Primary & -- & -- \\
\hline $\mathrm{P}_{2} \mathrm{O}_{5}$ & Primary & Common & Minor \\
\hline $\mathrm{ZnCl}_{2}$ & Primary & Abundant & Minor \\
\hline
\end{tabular}

Primary $>$ Abundant $>$ Common $>$ Minor $>$ Trace 
WSRC-TR-99-00479

Revision: 0

\section{Phase II}

\section{Non-Radioactive}

Archimedes density was performed on all of the non-radioactive samples. Table XIII is the average density and apparent porosity of three pellets produced with 0.6 moles impurity per mole plutonium (Ce) for each of the 48 batches. In the table, "TBE" is the impurity composition from Appendix B and "Sinter" is the grouping of the sintering cycles.

Table XIII. Density of A0/Ce/s Pellets with 0.6 Moles Impurity Per Mole Plutonium (Ce).

\begin{tabular}{|c|c|c|c|c|}
\hline A0/Ce/s & Apparent Porosity & Bulk Density $\left(\mathrm{g} / \mathrm{cm}^{3}\right)$ & TBE & Sinter \\
\hline Impurity-0a & $0.00 \%$ & 5.064 & Reference & 1 \\
\hline Impurity-0b & $0.81 \%$ & 5.011 & Reference & 2 \\
\hline Impurity-0c & $2.34 \%$ & 5.017 & Reference & 3 \\
\hline Impurity-1 & $0.79 \%$ & 4.801 & 1 & 1 \\
\hline Impurity-2 & $0.00 \%$ & 4.895 & 2 & 1 \\
\hline Impurity-3 & $1.49 \%$ & 4.828 & 3 & 1 \\
\hline Impurity-4 & $0.20 \%$ & 4.895 & 4 & 1 \\
\hline Impurity-5 & $0.61 \%$ & 4.935 & 5 & 1 \\
\hline Impurity-6 & $1.79 \%$ & 4.861 & 6 & 1 \\
\hline Impurity-7 & $0.19 \%$ & 4.667 & 7 & 1 \\
\hline Impurity-8 & $1.25 \%$ & 4.655 & 8 & 1 \\
\hline Impurity-9 & $3.14 \%$ & 4.599 & 9 & 1 \\
\hline Impurity-10 & $1.80 \%$ & 4.816 & 10 & 1 \\
\hline Impurity-11 & $1.09 \%$ & 4.863 & 11 & 1 \\
\hline Impurity-12 & $1.66 \%$ & 4.868 & 12 & 1 \\
\hline Impurity-13 & $0.91 \%$ & 4.883 & 13 & 1 \\
\hline Impurity-14 & $1.52 \%$ & 4.869 & 14 & 1 \\
\hline Impurity-15 & $1.01 \%$ & 4.876 & 15 & 1 \\
\hline Impurity-16a & $0.39 \%$ & 4.841 & Centroid & 1 \\
\hline Impurity-16b & $4.60 \%$ & 4.749 & Centroid & 2 \\
\hline Impurity-16c & $2.48 \%$ & 4.796 & Centroid & 3 \\
\hline Impurity-17 & $1.68 \%$ & 4.851 & 16 & 2 \\
\hline Impurity-18 & $0.91 \%$ & 4.915 & 17 & 2 \\
\hline Impurity-19 & $1.01 \%$ & 4.886 & 18 & 2 \\
\hline Impurity-20 & $0.30 \%$ & 4.950 & 19 & 2 \\
\hline Impurity-21 & $2.53 \%$ & 4.882 & 20 & 2 \\
\hline Impurity-22 & $1.01 \%$ & 4.907 & 21 & 2 \\
\hline Impurity-23 & $1.99 \%$ & 4.829 & 22 & 2 \\
\hline Impurity-24 & $0.61 \%$ & 4.911 & 23 & 2 \\
\hline Impurity-25 & $1.00 \%$ & 4.884 & 24 & 2 \\
\hline Impurity-26 & $1.32 \%$ & 4.883 & 25 & 2 \\
\hline Impurity-27 & $0.51 \%$ & 4.938 & 26 & 2 \\
\hline Impurity-28 & $0.31 \%$ & 4.934 & 27 & 2 \\
\hline Impurity-29 & $0.51 \%$ & 4.896 & 28 & 2 \\
\hline- continued-- & & \\
\hline
\end{tabular}


--continued--

\begin{tabular}{|c|c|c|c|c|}
\hline A0/Ce/s & Apparent Porosity & Bulk Density $\left(\mathrm{g} / \mathrm{cm}^{3}\right)$ & TBE & Sinter \\
\hline Impurity-30 & $1.43 \%$ & 4.907 & 29 & 2 \\
\hline Impurity-31 & $0.70 \%$ & 4.819 & 30 & 2 \\
\hline Impurity-32 & $0.70 \%$ & 4.911 & Centroid & 2 \\
\hline Impurity-33 & $0.31 \%$ & 4.939 & 31 & 3 \\
\hline Impurity-34 & $0.82 \%$ & 4.884 & 32 & 3 \\
\hline Impurity-35 & $0.41 \%$ & 4.907 & 33 & 3 \\
\hline Impurity-36 & $1.89 \%$ & 4.770 & 34 & 3 \\
\hline Impurity-37 & $0.90 \%$ & 4.919 & 35 & 3 \\
\hline Impurity-38 & $1.58 \%$ & 4.809 & 36 & 3 \\
\hline Impurity-39 & $2.21 \%$ & 4.851 & 37 & 3 \\
\hline Impurity-40 & $1.81 \%$ & 4.879 & 38 & 3 \\
\hline Impurity-41 & $2.02 \%$ & 4.873 & 39 & 3 \\
\hline Impurity-42 & $1.62 \%$ & 4.915 & 40 & 3 \\
\hline Impurity-43 & $0.30 \%$ & 4.949 & 41 & 3 \\
\hline Impurity-44 & $0.90 \%$ & 4.847 & 42 & 3 \\
\hline Impurity-45 & $0.91 \%$ & 4.853 & 43 & 3 \\
\hline Impurity-46 & $1.30 \%$ & 4.848 & 44 & 3 \\
\hline Impurity-47 & $0.90 \%$ & 4.839 & 45 & 3 \\
\hline Impurity-48 & $1.29 \%$ & 4.815 & Centroid & 3 \\
\hline
\end{tabular}

In the case of composition Impurity-16, pellets that were sintered in different sintering cycles were appended with "a," "b," and "c." At 0.6 mole impurity per mole plutonium (Ce), for each impurity composition, the apparent porosity was similar to that of the baseline reference pellets. Table XIV is the XRD results for one pellet of each composition. The intensity of the most discernible peak of each phase was normalized to the intensity of the largest pyrochlore peak. The percentage given for each of the phases therefore does not indicate the specific amount of the phase that has been detected. As stated previously, the main zirconolite peak near $30^{\circ} 2 \theta$ is masked by the primary pyrochlore peak so a secondary peak was used to determine relative intensities. The main interest in Phase $\Pi$ is the relative effect of the combination of impurities on the formation of the individual phases. Therefore, the normalized intensity of the zirconolite peaks, while not providing the absolute amount of zirconolite present, provides a value for sample-to-sample comparisons of the relative amounts of zirconolite to pyrochlore. 
Table XIV. Relative Intensities of Phases Detected in Impurity Matrix Pellets with 0.6 Moles Impurity per Mole Plutonium (Ce).

\begin{tabular}{|c|c|c|c|c|c|c|}
\hline A0/Ce/s & Pyrochlore & Rutile & Perovskite & Zirconolite & TBE & Sinter \\
\hline Impurity-0a & $100 \%$ & $4 \%$ & $3 \%$ & $0 \%$ & Reference & 1 \\
\hline Impurity-0b & $100 \%$ & $5 \%$ & $5 \%$ & $0 \%$ & Reference & 2 \\
\hline Impurity-0c & $100 \%$ & $5 \%$ & $5 \%$ & $0 \%$ & Reference & 3 \\
\hline Impurity-1 & $100 \%$ & $7 \%$ & $6 \%$ & $6 \%$ & 1 & 1 \\
\hline Impurity-2 & $100 \%$ & $3 \%$ & $8 \%$ & $5 \%$ & 2 & 1 \\
\hline Impurity-3 & $100 \%$ & $5 \%$ & $8 \%$ & $4 \%$ & 3 & 1 \\
\hline Impurity-4 & $100 \%$ & $3 \%$ & $6 \%$ & $4 \%$ & 4 & 1 \\
\hline Impurity-5 & $100 \%$ & $4 \%$ & $9 \%$ & $5 \%$ & 5 & 1 \\
\hline Impurity-6 & $100 \%$ & $3 \%$ & $9 \%$ & $4 \%$ & 6 & 1 \\
\hline Impurity-7 & $100 \%$ & $8 \%$ & $6 \%$ & $3 \%$ & 7 & 1 \\
\hline Impurity-8 & $100 \%$ & $6 \%$ & $6 \%$ & $0 \%$ & 8 & 1 \\
\hline Impurity-9 & $100 \%$ & $6 \%$ & $8 \%$ & $0 \%$ & 9 & 1 \\
\hline Impurity-10 & $100 \%$ & $0 \%$ & $9 \%$ & $8 \%$ & 10 & 1 \\
\hline Impurity-11 & $100 \%$ & $0 \%$ & $13 \%$ & $9 \%$ & 11 & 1 \\
\hline Impurity-12 & $100 \%$ & $5 \%$ & $6 \%$ & $5 \%$ & 12 & 1 \\
\hline Impurity-13 & $100 \%$ & $5 \%$ & $11 \%$ & $6 \%$ & 13 & 1 \\
\hline Impurity-14 & $100 \%$ & $0 \%$ & $11 \%$ & $6 \%$ & 14 & 1 \\
\hline Impurity-15 & $100 \%$ & $5 \%$ & $8 \%$ & $6 \%$ & 15 & 1 \\
\hline Impurity-16a & $100 \%$ & $6 \%$ & $7 \%$ & $5 \%$ & centroid & 1 \\
\hline Impurity-16b & $100 \%$ & $5 \%$ & $6 \%$ & $5 \%$ & centroid & 2 \\
\hline Impurity-16c & $100 \%$ & $4 \%$ & $7 \%$ & $5 \%$ & centroid & 3 \\
\hline Impurity-17 & $100 \%$ & $3 \%$ & $6 \%$ & $5 \%$ & 16 & 2 \\
\hline Impurity-18 & $100 \%$ & $5 \%$ & $8 \%$ & $7 \%$ & 17 & 2 \\
\hline Impurity-19 & $100 \%$ & $4 \%$ & $6 \%$ & $4 \%$ & 18 & 2 \\
\hline Impurity-20 & $100 \%$ & $6 \%$ & $11 \%$ & $7 \%$ & 19 & 2 \\
\hline Impurity-21 & $100 \%$ & $5 \%$ & $13 \%$ & $5 \%$ & 20 & 2 \\
\hline Impurity-22 & $100 \%$ & $5 \%$ & $11 \%$ & $5 \%$ & 21 & 2 \\
\hline Impurity-23 & $100 \%$ & $4 \%$ & $5 \%$ & $5 \%$ & 22 & 2 \\
\hline Impurity-24 & $100 \%$ & $6 \%$ & $5 \%$ & $4 \%$ & 23 & 2 \\
\hline Impurity-25 & $100 \%$ & $5 \%$ & $6 \%$ & $3 \%$ & 24 & 2 \\
\hline Impurity-26 & $100 \%$ & $5 \%$ & $15 \%$ & $6 \%$ & 25 & 2 \\
\hline Impurity-27 & $100 \%$ & $5 \%$ & $15 \%$ & $5 \%$ & 26 & 2 \\
\hline Impurity-28 & $100 \%$ & $7 \%$ & $22 \%$ & $7 \%$ & 27 & 2 \\
\hline Impurity-29 & $100 \%$ & $3 \%$ & $7 \%$ & $4 \%$ & 28 & 2 \\
\hline Impurity-30 & $100 \%$ & $5 \%$ & $8 \%$ & $6 \%$ & 29 & 2 \\
\hline Impurity-31 & $100 \%$ & $5 \%$ & $6 \%$ & $4 \%$ & 30 & 2 \\
\hline Impurity-32 & $100 \%$ & $7 \%$ & $7 \%$ & $6 \%$ & Centroid & 2 \\
\hline Impurity-33 & $100 \%$ & $3 \%$ & $9 \%$ & $7 \%$ & 31 & 3 \\
\hline Impurity-34 & $100 \%$ & $5 \%$ & $10 \%$ & $5 \%$ & 32 & 3 \\
\hline Impurity-35 & $100 \%$ & $4 \%$ & $8 \%$ & $4 \%$ & 33 & 3 \\
\hline
\end{tabular}


--continued--

\begin{tabular}{|c|c|c|c|c|c|c|}
\hline $\mathrm{A} 0 / \mathrm{Ce} / \mathrm{s}$ & Pyrochlore & Rutile & Perovskite & Zirconolite & TBE & Sinter \\
\hline Impurity-36 & $100 \%$ & $8 \%$ & $6 \%$ & $5 \%$ & 34 & 3 \\
\hline Impurity-37 & $100 \%$ & $6 \%$ & $5 \%$ & $3 \%$ & 35 & 3 \\
\hline Impurity-38 & $100 \%$ & $8 \%$ & $6 \%$ & $6 \%$ & 36 & 3 \\
\hline Impurity-39 & $100 \%$ & $5 \%$ & $4 \%$ & $3 \%$ & 37 & 3 \\
\hline Impurity-40 & $100 \%$ & $6 \%$ & $6 \%$ & $3 \%$ & 38 & 3 \\
\hline Impurity-41 & $100 \%$ & $5 \%$ & $4 \%$ & $3 \%$ & 39 & 3 \\
\hline Impurity-42 & $100 \%$ & $5 \%$ & $8 \%$ & $10 \%$ & 40 & 3 \\
\hline Impurity-43 & $100 \%$ & $3 \%$ & $7 \%$ & $7 \%$ & 41 & 3 \\
\hline Impurity-44 & $100 \%$ & $5 \%$ & $6 \%$ & $7 \%$ & 42 & 3 \\
\hline Impurity-45 & $100 \%$ & $4 \%$ & $6 \%$ & $5 \%$ & 43 & 3 \\
\hline Impurity-46 & $100 \%$ & $6 \%$ & $8 \%$ & $6 \%$ & 44 & 3 \\
\hline Impurity-47 & $100 \%$ & $5 \%$ & $6 \%$ & $3 \%$ & 45 & 3 \\
\hline Impurity-48 & $100 \%$ & $5 \%$ & $5 \%$ & $5 \%$ & Centroid & 3 \\
\hline
\end{tabular}

Perfunctory appraisal of both the apparent porosity and the phase assemblage of the impurity matrix pellets indicate that 0.6 moles of impurity per mole of plutonium $(\mathrm{Ce})$ may be a conservative estimate of the ability of the ceramic form to accommodate impurities. Table $\mathrm{XV}$ is the average density and apparent porosity of impurity pellets made with 0.8 moles of impurities per mole plutonium (Ce). As with the previous series of pellets, the apparent porosity was not noticeably affected by any combination of the impurity mixtures attempted. Only sample Impurity-82 (TBE composition 32) showed any indication of an adverse effect. The sample had maximum potassium levels. The remaining fourteen impurities were present in equivalent amounts. All of the pellets of that composition had broken. This may have caused poor measurement of the porosity and been the result of poorly fabricated pellets. There is also the possibility that the pellet fracture was due to a disagreeable impurity composition. Pellet integrity problems (disintegration) were observed in potassium impurity pellets in the single impurity addition series.

Table XV. Density of A0/Ce/s Pellets with 0.8 Moles Impurity Per Mole Plutonium (Ce).

\begin{tabular}{|c|c|c|c|c|}
\hline $\mathrm{A} 0 / \mathrm{Ce} / \mathrm{s}$ & Apparent Porosity & bulk density $\left(\mathrm{g} / \mathrm{cm}^{3}\right)$ & TBE & Sinter \\
\hline Impurity-0d & $0.40 \%$ & 5.039 & Base & 4 \\
\hline Impurity-0e & $0.09 \%$ & 5.053 & Base & 5 \\
\hline Impurity-0f & $1.30 \%$ & 5.010 & Base & 6 \\
\hline Impurity-49 & $1.30 \%$ & 4.821 & 1 & 4 \\
\hline Impurity-50 & $1.39 \%$ & 4.802 & 2 & 4 \\
\hline Impurity-51 & $1.20 \%$ & 4.884 & 3 & 4 \\
\hline Impurity-52 & $0.69 \%$ & 4.838 & 4 & 4 \\
\hline Impurity-53 & $1.68 \%$ & 4.844 & 5 & 4 \\
\hline Impurity-54 & $1.09 \%$ & 4.869 & 6 & 4 \\
\hline Impurity-55 & $1.13 \%$ & 4.587 & 7 & 4 \\
\hline Impurity-56 & $1.04 \%$ & 4.633 & 8 & 4 \\
\hline
\end{tabular}

--continued-- 
--continued--

\begin{tabular}{|l|c|c|c|c|}
\hline A0/Ce/s & Apparent Porosity & bulk density $\left(\mathrm{g} / \mathrm{cm}^{3}\right)$ & TBE & Sinter \\
\hline Impurity-57 & $1.94 \%$ & 4.647 & 9 & 4 \\
\hline Impurity-58 & $1.48 \%$ & 4.848 & 10 & 4 \\
\hline Impurity-59 & $1.38 \%$ & 4.865 & 11 & 4 \\
\hline Impurity-60 & $2.23 \%$ & 4.799 & 12 & 4 \\
\hline Impurity-61 & $0.84 \%$ & 4.935 & 13 & 4 \\
\hline Impurity-62 & $0.99 \%$ & 4.890 & 14 & 4 \\
\hline Impurity-63 & $1.40 \%$ & 4.836 & 15 & 4 \\
\hline Impurity-64a & $1.31 \%$ & 4.856 & centroid & 4 \\
\hline Impurity-64b & $1.12 \%$ & 4.853 & centroid & 5 \\
\hline Impurity-64c & $0.90 \%$ & 4.876 & centroid & 6 \\
\hline Impurity-65 & $1.29 \%$ & 4.864 & 16 & 5 \\
\hline Impurity-66 & $0.91 \%$ & 4.924 & 17 & 5 \\
\hline Impurity-67 & $1.29 \%$ & 4.882 & 18 & 5 \\
\hline Impurity-68 & $0.69 \%$ & 4.829 & 19 & 5 \\
\hline Impurity-69 & $1.37 \%$ & 4.853 & 20 & 5 \\
\hline Impurity-70 & $1.28 \%$ & 4.839 & 21 & 5 \\
\hline Impurity-71 & $0.55 \%$ & 5.115 & 22 & 5 \\
\hline Impurity-72 & $0.59 \%$ & 4.913 & 23 & 5 \\
\hline Impurity-73 & $0.97 \%$ & 4.889 & 24 & 5 \\
\hline Impurity-74 & $1.08 \%$ & 4.866 & 25 & 5 \\
\hline Impurity-75 & $2.22 \%$ & 4.825 & 26 & 5 \\
\hline Impurity-76 & $1.66 \%$ & 4.855 & 27 & 5 \\
\hline Impurity-77 & $0.99 \%$ & 4.812 & 28 & 5 \\
\hline Impurity-78 & $0.50 \%$ & 4.973 & 29 & 5 \\
\hline Impurity-79 & $1.38 \%$ & 4.849 & 30 & 5 \\
\hline Impurity-80 & $0.29 \%$ & 4.878 & centroid & 5 \\
\hline Impurity-81 & $3.47 \%$ & 4.794 & 31 & 6 \\
\hline Impurity-82 & $7.23 \%$ & 4.727 & 32 & 6 \\
\hline Impurity-83 & $2.57 \%$ & 4.823 & 33 & 6 \\
\hline Impurity-84 & $3.81 \%$ & 4.654 & 34 & 6 \\
\hline Impurity-85 & $1.17 \%$ & 4.817 & 35 & 6 \\
\hline Impurity-86 & $1.36 \%$ & 4.766 & 36 & 6 \\
\hline Impurity-87 & $1.27 \%$ & 4.795 & 37 & 6 \\
\hline Impurity-88 & $1.45 \%$ & 4.785 & 38 & 6 \\
\hline Impurity-89 & $3.91 \%$ & 4.659 & 39 & 6 \\
\hline Impurity-90 & $2.11 \%$ & 5.143 & 40 & 6 \\
\hline Impurity-91 & $1.47 \%$ & 4.888 & 41 & 6 \\
\hline Impurity-92 & $1.89 \%$ & 4.912 & 42 & 6 \\
\hline Impurity-93 & $2.65 \%$ & 4.787 & 43 & 6 \\
\hline Impurity-94 & $1.96 \%$ & 4.793 & 44 & 6 \\
\hline Impurity-95 & $1.76 \%$ & 4.821 & 45 & 6 \\
\hline Impurity-96 & $3.28 \%$ & 4.767 & centroid & 6 \\
\hline
\end{tabular}


Table XVI is the XRD summary for the non-radioactive impurity pellets with 0.8 mole impurity per mole plutonium (Ce). Again, each composition investigated resulted in pellets that had mineralogy consistent with the specifications in Reference 1.

Table XVI. Relative Intensities of Phases Detected in Non-Radioactive Impurity Matrix Pellets with 0.8 Moles Impurity per Mole Plutonium (Ce).

\begin{tabular}{|c|c|c|c|c|c|c|}
\hline A0/Ce/s & Pyrochlore & Rutile & Perovskite & Zirconolite & TBE & Sinter \\
\hline Impurity-0d & $100 \%$ & $3 \%$ & $4 \%$ & $0 \%$ & Reference & 4 \\
\hline Impurity-0e & $100 \%$ & $5 \%$ & $5 \%$ & $0 \%$ & Reference & 5 \\
\hline Impurity-0f & $100 \%$ & $5 \%$ & $5 \%$ & $0 \%$ & Reference & 6 \\
\hline Impurity-49 & $100 \%$ & $5 \%$ & $8 \%$ & $6 \%$ & 1 & 4 \\
\hline Impurity-50 & $100 \%$ & $5 \%$ & $7 \%$ & $8 \%$ & 2 & 4 \\
\hline Impurity-51 & $100 \%$ & $5 \%$ & $8 \%$ & $7 \%$ & 3 & 4 \\
\hline Impurity-52 & $100 \%$ & $0 \%$ & $10 \%$ & $6 \%$ & 4 & 4 \\
\hline Impurity-53 & $100 \%$ & $10 \%$ & $12 \%$ & $8 \%$ & 5 & 4 \\
\hline Impurity-54 & $100 \%$ & $4 \%$ & $12 \%$ & $7 \%$ & 6 & 4 \\
\hline Impurity-55 & $100 \%$ & $6 \%$ & $4 \%$ & $7 \%$ & 7 & 4 \\
\hline Impurity-56 & $100 \%$ & $6 \%$ & $8 \%$ & $6 \%$ & 8 & 4 \\
\hline Impurity-57 & $100 \%$ & $7 \%$ & $6 \%$ & $5 \%$ & 9 & 4 \\
\hline Impurity-58 & $100 \%$ & $0 \%$ & $14 \%$ & $3 \%$ & 10 & 4 \\
\hline Impurity-59 & $100 \%$ & $0 \%$ & $10 \%$ & $5 \%$ & 11 & 4 \\
\hline Impurity-60 & $100 \%$ & $8 \%$ & $7 \%$ & $5 \%$ & 12 & 4 \\
\hline Impurity-61 & $100 \%$ & $0 \%$ & $10 \%$ & $10 \%$ & 13 & 4 \\
\hline Impurity-62 & $100 \%$ & $0 \%$ & $12 \%$ & $10 \%$ & 14 & 4 \\
\hline Impurity-63 & $100 \%$ & $0 \%$ & $10 \%$ & $9 \%$ & 15 & 4 \\
\hline Impurity-64a & $100 \%$ & $6 \%$ & $8 \%$ & $7 \%$ & centroid & 4 \\
\hline Impurity-64b & $100 \%$ & $7 \%$ & $11 \%$ & $8 \%$ & centroid & 5 \\
\hline Impurity-64c & $100 \%$ & $6 \%$ & $10 \%$ & $10 \%$ & centroid & 6 \\
\hline Impurity-65 & $100 \%$ & $3 \%$ & $7 \%$ & $8 \%$ & 16 & 5 \\
\hline Impurity-66 & $100 \%$ & $4 \%$ & $8 \%$ & $10 \%$ & 17 & 5 \\
\hline Impurity-67 & $100 \%$ & $5 \%$ & $8 \%$ & $8 \%$ & 18 & 5 \\
\hline Impurity-68 & $100 \%$ & $3 \%$ & $10 \%$ & $8 \%$ & 19 & 5 \\
\hline Impurity-69 & $100 \%$ & $6 \%$ & $14 \%$ & $8 \%$ & 20 & 5 \\
\hline Impurity-70 & $100 \%$ & $5 \%$ & $12 \%$ & $8 \%$ & 21 & 5 \\
\hline Impurity-71 & $100 \%$ & $6 \%$ & $7 \%$ & $7 \%$ & 22 & 5 \\
\hline Impurity-72 & $100 \%$ & $5 \%$ & $5 \%$ & $8 \%$ & 23 & 5 \\
\hline Impurity-73 & $100 \%$ & $8 \%$ & $5 \%$ & $5 \%$ & 24 & 5 \\
\hline Impurity-74 & $100 \%$ & $3 \%$ & $15 \%$ & $7 \%$ & 25 & 5 \\
\hline Impurity-75 & $100 \%$ & $6 \%$ & $17 \%$ & $9 \%$ & 26 & 5 \\
\hline Impurity-76 & $100 \%$ & $5 \%$ & $16 \%$ & $7 \%$ & 27 & 5 \\
\hline Impurity-77 & $100 \%$ & $0 \%$ & $12 \%$ & $8 \%$ & 28 & 5 \\
\hline Impurity-78 & $100 \%$ & $3 \%$ & $8 \%$ & $5 \%$ & 29 & 5 \\
\hline Impurity-79 & $100 \%$ & $9 \%$ & $10 \%$ & $7 \%$ & 30 & 5 \\
\hline
\end{tabular}


--continued--

\begin{tabular}{|c|c|c|c|c|c|c|}
\hline A0/Ce/s & Pyrochlore & Rutile & Perovskite & Zirconolite & TBE & Sinter \\
\hline Impurity-80 & $100 \%$ & $3 \%$ & $10 \%$ & $6 \%$ & Centroid & 5 \\
\hline Impurity-81 & $100 \%$ & $7 \%$ & $12 \%$ & $10 \%$ & 31 & 6 \\
\hline Impurity-82 & $100 \%$ & $3 \%$ & $10 \%$ & $6 \%$ & 32 & 6 \\
\hline Impurity-83 & $100 \%$ & $7 \%$ & $15 \%$ & $8 \%$ & 33 & 6 \\
\hline Impurity-84 & $100 \%$ & $7 \%$ & $5 \%$ & $5 \%$ & 34 & 6 \\
\hline Impurity-85 & $100 \%$ & $8 \%$ & $6 \%$ & $6 \%$ & 35 & 6 \\
\hline Impurity-86 & $100 \%$ & $5 \%$ & $3 \%$ & $3 \%$ & 36 & 6 \\
\hline Impurity-87 & $100 \%$ & $2 \%$ & $2 \%$ & $3 \%$ & 37 & 6 \\
\hline Impurity-88 & $100 \%$ & $6 \%$ & $5 \%$ & $5 \%$ & 38 & 6 \\
\hline Impurity-89 & $100 \%$ & $5 \%$ & $4 \%$ & $3 \%$ & 39 & 6 \\
\hline Impurity-90 & $100 \%$ & $0 \%$ & $8 \%$ & $10 \%$ & 40 & 6 \\
\hline Impurity-91 & $100 \%$ & $5 \%$ & $5 \%$ & $11 \%$ & 41 & 6 \\
\hline Impurity-92 & $100 \%$ & $0 \%$ & $12 \%$ & $10 \%$ & 42 & 6 \\
\hline Impurity-93 & $100 \%$ & $5 \%$ & $9 \%$ & $8 \%$ & 43 & 6 \\
\hline Impurity-94 & $100 \%$ & $6 \%$ & $8 \%$ & $6 \%$ & 44 & 6 \\
\hline Impurity-95 & $100 \%$ & $8 \%$ & $8 \%$ & $5 \%$ & 45 & 6 \\
\hline Impurity-96 & $100 \%$ & $5 \%$ & $8 \%$ & $6 \%$ & Centroid & 6 \\
\hline
\end{tabular}

Enough of the baseline A0/Ce/s powder remained to produce three large pellets (115 $\mathrm{g}, 2.125$ in diameter). Three compositions, Impurity-57, -84 and -89 were selected to produce the large pellets. These compositions correspond to TBE-9 (maximum $\mathrm{B}_{2} \mathrm{O}_{3}$, high $\mathrm{MoO}_{3}$ and high $\mathrm{P}_{2} \mathrm{O}_{5}$ ), TBE-34 (maximum $\mathrm{P}_{2} \mathrm{O}_{5}$ and high $\mathrm{B}_{2} \mathrm{O}_{3}$ ), and TBE-39 (maximum $\mathrm{MoO}_{3}$ and high $\mathrm{P}_{2} \mathrm{O}_{5}$ ), respectively. Figure 1 is a photograph of the three large impurity pellets. The pellets displayed blisters from the impurity interactions as well as interactions with the zirconia setter material. However, discoloration and blistering are not necessarily indications of high porosity or mineralogy instability. Table XVII is the density and the apparent porosity for the large pellets of the three compositions produced.

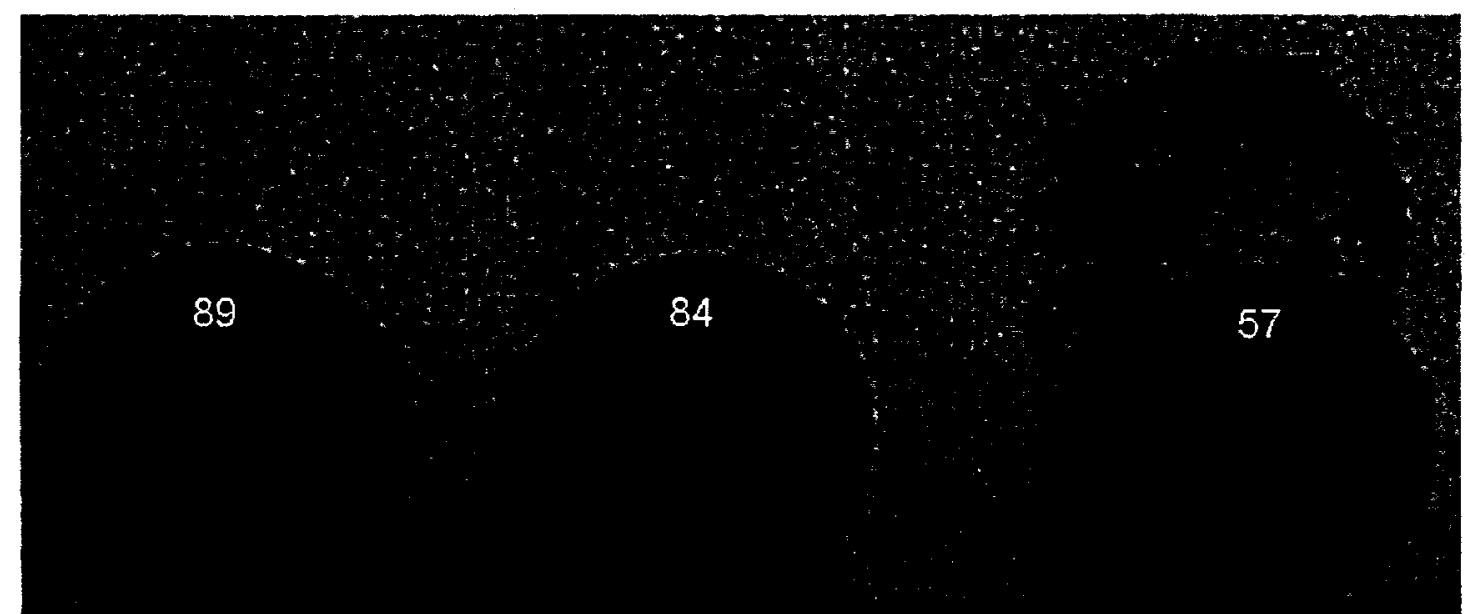

Figure 1. Large impurity pellets (Impurity-89, -84 and -57 ) sintered on porous yttriastabilized zirconia. 
Table XVII. Archimedes Density of the Large Impurity Pellets.

\begin{tabular}{|l|c|c|c|}
\hline Impurity ID & TBE ID & Apparent Porosity & Bulk Density $\left(\mathrm{g} / \mathrm{cm}^{3}\right)$ \\
\hline Impurity-57 & 9 & $1.44 \%$ & 4.55 \\
\hline Impurity-84 & 34 & $0.93 \%$ & 4.57 \\
\hline Impurity-89 & 39 & $15.89 \%$ & 4.06 \\
\hline
\end{tabular}

Density results for compositions NRP-A0-57 and NRP-A0-84 showed a slight increase in the apparent porosity in larger pellets when compared to smaller pellets of the same composition. In the NRP-A0-89 large pellet, the apparent porosity was more than two times greater than that of comparable smaller pellets. However, only one large pellet was produced for each composition and this may not truly represent the behavior of the composition. XRD results indicated that scaling does not appear to affect the mineralogy of the impurity pellets. All three compositions resulted in pyrochlore as the primary phase, with minor amounts of rutile, and trace quantities of perovskite. NRP-A0-84 may have also contained a vitreous phase. This composition is rich in phosphorus with elevated amounts of boron and fluorine.

\section{Actinide}

Archimedes density was performed on all of the actinide samples made with uranium. Table XVIII is the average density and apparent porosity of three pellets produced with 0.8 moles impurity per mole plutonium (Ce) for each of the 48 batches. Several of the impurity compositions resulted in pellets with an average apparent porosity greater than ten percent. Four of the impurity compositions possessed an apparent porosity above twenty percent and three other compositions had apparent porosity above thirty percent. A statistical analysis of the effect of the impurities on the apparent porosity and the amount of phases other than pyrochlore was performed. The responses of interest are the apparent porosity and the phase assemblage.

Table XVIII. Density of A0/Ce Pellets with 0.8 Moles Impurity Per Mole Plutonium (Ce).

\begin{tabular}{|c|c|c|c|c|}
\hline $\mathrm{A} 0 / \mathrm{Ce}$ & Apparent Porosity & Bulk Density $\left(\mathrm{g} / \mathrm{cm}^{3}\right)$ & TBE & Sinter \\
\hline Impurity-0a & $2.37 \%$ & 5.307 & Reference & 1 \\
\hline Impurity-0b & $2.15 \%$ & 5.274 & Reference & 2 \\
\hline Impurity-0c & $1.62 \%$ & 5.317 & Reference & 3 \\
\hline Impurity-49 & $6.86 \%$ & 4.914 & 1 & 1 \\
\hline Impurity-50 & $9.94 \%$ & 4.791 & 2 & 1 \\
\hline Impurity-51 & $11.15 \%$ & 4.664 & 3 & 1 \\
\hline Impurity-52 & $4.95 \%$ & 5.023 & 4 & 1 \\
\hline Impurity-53 & $5.59 \%$ & 4.930 & 5 & 1 \\
\hline Impurity-54 & $10.58 \%$ & 4.698 & 6 & 1 \\
\hline Impurity-55 & $15.11 \%$ & 4.375 & 7 & 1 \\
\hline Impurity-56 & $11.34 \%$ & 4.623 & 8 & 1 \\
\hline Impurity-57 & $14.64 \%$ & 4.548 & 9 & 1 \\
\hline Impurity-58 & $1.97 \%$ & 5.059 & 10 & 1 \\
\hline Impurity-59 & $6.89 \%$ & 4.892 & 11 & 1 \\
\hline
\end{tabular}


--continued--

\begin{tabular}{|c|c|c|c|c|}
\hline $\mathrm{A} 0 / \mathrm{Ce}$ & Apparent Porosity & 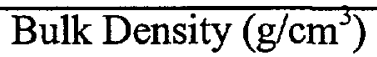 & TBE & Sinter \\
\hline Impurity-60 & $6.19 \%$ & 4.817 & 12 & 1 \\
\hline Impurity-61 & $1.09 \%$ & 5.087 & 13 & 1 \\
\hline Impurity-62 & $4.04 \%$ & 4.829 & 14 & 1 \\
\hline Impurity-63 & $11.74 \%$ & 4.599 & 15 & 1 \\
\hline Impurity-64a & $18.00 \%$ & 4.347 & Centroid & 1 \\
\hline Impurity-64b & $11.06 \%$ & 4.734 & Centroid & 2 \\
\hline Impurity-64c & $12.62 \%$ & 4.698 & Centroid & 3 \\
\hline Impurity-65 & $5.00 \%$ & 5.032 & 16 & 2 \\
\hline Impurity-66 & $7.16 \%$ & 4.862 & 17 & 2 \\
\hline Impurity-67 & $8.63 \%$ & 4.855 & 18 & $\overline{2}$ \\
\hline Impurity-68 & $3.42 \%$ & 5.036 & 19 & 2 \\
\hline Impurity-69 & $10.03 \%$ & 4.709 & 20 & 2 \\
\hline Impurity-70 & $18.28 \%$ & 4.381 & 21 & 2 \\
\hline Impurity-71 & $3.39 \%$ & 5.045 & 22 & 2 \\
\hline Impurity-72 & $7.52 \%$ & 4.872 & 23 & 2 \\
\hline Impurity-73 & $23.39 \%$ & 4.195 & 24 & 2 \\
\hline Impurity-74 & $1.45 \%$ & 5.152 & 25 & 2 \\
\hline Impurity -75 & $4.17 \%$ & 5.013 & 26 & 2 \\
\hline Impurity-76 & $8.09 \%$ & 4.807 & 27 & 2 \\
\hline Impurity-77 & $2.14 \%$ & 5.093 & 28 & 2 \\
\hline Impurity-78 & $7.89 \%$ & 4.884 & 29 & 2 \\
\hline Impurity-79 & $18.54 \%$ & 4.419 & 30 & 2 \\
\hline Impurity-80 & $9.77 \%$ & 4.778 & Centroid & 2 \\
\hline Impurity-81 & $19.27 \%$ & 4.386 & 31 & 3 \\
\hline Impurity-82 & $11.40 \%$ & 4.736 & 32 & 3 \\
\hline Impurity-83 & $18.28 \%$ & 4.496 & 33 & 3 \\
\hline Impurity-84 & $13.75 \%$ & 4.659 & 34 & 3 \\
\hline Impurity-86 & $30.92 \%$ & 3.791 & 36 & 3 \\
\hline Impurity-87 & $23.40 \%$ & 4.207 & 37 & 3 \\
\hline Impurity-88 & $32.14 \%$ & 3.780 & 38 & 3 \\
\hline Impurity-89 & $30.52 \%$ & 3.899 & 39 & 3 \\
\hline Impurity-90 & $5.97 \%$ & 4.910 & 40 & 3 \\
\hline Impurity-91 & $6.37 \%$ & 4.938 & 41 & 3 \\
\hline Impurity-92 & $6.75 \%$ & 4.894 & 42 & 3 \\
\hline Impurity-93 & $9.25 \%$ & 4.778 & 43 & 3 \\
\hline Impurity-94 & $20.40 \%$ & 4.480 & 44 & 3 \\
\hline Impurity-95 & $16.60 \%$ & 4.512 & 45 & 3 \\
\hline Impurity-96 & $14.65 \%$ & 4.537 & Centroid & 3 \\
\hline
\end{tabular}


Table XIX is the relative intensities of the phases detected in the baseline composition alone and with the impurities added. The reference XRD pattern indicates a primary phase of pyrochlore with minor amounts of brannerite and rutile. Zirconolite is the only additional phase noted that is not related to the reference pellet. All of the impurity compositions investigated resulted in pellets that had mineralogy consistent with the specifications in Reference 1.

Table XIX. Relative Intensities of Phases Detected in Actinide Impurity Matrix Pellets with 0.8 Moles Impurity per Mole Plutonium (Ce).

\begin{tabular}{|c|c|c|c|c|c|c|}
\hline A0/Ce & Pyrochlore & Brannerite & Rutile & Zirconolite & TBE & Sinter \\
\hline Impurity-0a & $100 \%$ & $0 \%$ & $0 \%$ & $0 \%$ & blank & 1 \\
\hline Impurity-0b & $100 \%$ & $12 \%$ & $10 \%$ & $0 \%$ & blank & 2 \\
\hline Impurity-0c & $100 \%$ & $11 \%$ & $12 \%$ & $0 \%$ & blank & 3 \\
\hline Impurity-49 & $100 \%$ & $4 \%$ & $14 \%$ & $0 \%$ & 1 & 1 \\
\hline Impurity-50 & $100 \%$ & $13 \%$ & $14 \%$ & $0 \%$ & 2 & 1 \\
\hline Impurity-51 & $100 \%$ & $5 \%$ & $12 \%$ & $0 \%$ & 3 & 1 \\
\hline Impurity-52 & $100 \%$ & $4 \%$ & $8 \%$ & $0 \%$ & 4 & 1 \\
\hline Impurity-53 & $100 \%$ & $8 \%$ & $0 \%$ & $0 \%$ & 5 & 1 \\
\hline Impurity-54 & $100 \%$ & $4 \%$ & $12 \%$ & $0 \%$ & 6 & 1 \\
\hline Impurity-55 & $100 \%$ & $9 \%$ & $11 \%$ & $0 \%$ & 7 & 1 \\
\hline Impurity-56 & $100 \%$ & $13 \%$ & $15 \%$ & $0 \%$ & 8 & 1 \\
\hline Impurity-57 & $100 \%$ & $11 \%$ & $14 \%$ & $0 \%$ & 9 & 1 \\
\hline Impurity-58 & $100 \%$ & $3 \%$ & $6 \%$ & $8 \%$ & 10 & 1 \\
\hline Impurity-59 & $100 \%$ & $6 \%$ & $10 \%$ & $5 \%$ & 11 & 1 \\
\hline Impurity-60 & $100 \%$ & $4 \%$ & $11 \%$ & $10 \%$ & 12 & 1 \\
\hline Impurity-61 & $100 \%$ & $0 \%$ & $11 \%$ & $0 \%$ & 13 & 1 \\
\hline Impurity-62 & $100 \%$ & $6 \%$ & $10 \%$ & $0 \%$ & 14 & 1 \\
\hline Impurity-63 & $100 \%$ & $5 \%$ & $14 \%$ & $0 \%$ & 15 & 1 \\
\hline Impurity-64a & $100 \%$ & $6 \%$ & $14 \%$ & $0 \%$ & centroid & 1 \\
\hline Impurity-64b & $100 \%$ & $5 \%$ & $12 \%$ & $0 \%$ & centroid & 2 \\
\hline Impurity-64c & $100 \%$ & $8 \%$ & $12 \%$ & $0 \%$ & centroid & 3 \\
\hline Impurity-65 & $100 \%$ & $5 \%$ & $9 \%$ & $0 \%$ & 16 & 2 \\
\hline Impurity-66 & $100 \%$ & $9 \%$ & $13 \%$ & $0 \%$ & 17 & 2 \\
\hline Impurity-67 & $100 \%$ & $4 \%$ & $11 \%$ & $5 \%$ & 18 & 2 \\
\hline Impurity-68 & $100 \%$ & $0 \%$ & $11 \%$ & $0 \%$ & 19 & 2 \\
\hline Impurity-69 & $100 \%$ & $0 \%$ & $11 \%$ & $0 \%$ & 20 & 2 \\
\hline Impurity-70 & $100 \%$ & $0 \%$ & $13 \%$ & $0 \%$ & 21 & 2 \\
\hline Impurity-71 & $100 \%$ & $7 \%$ & $10 \%$ & $0 \%$ & 22 & 2 \\
\hline Impurity-72 & $100 \%$ & $8 \%$ & $10 \%$ & $0 \%$ & 23 & 2 \\
\hline Impurity-73 & $100 \%$ & $10 \%$ & $12 \%$ & $0 \%$ & 24 & 2 \\
\hline Impurity-74 & $100 \%$ & $0 \%$ & $6 \%$ & $9 \%$ & 25 & 2 \\
\hline Impurity-75 & $100 \%$ & $0 \%$ & $8 \%$ & $6 \%$ & 26 & 2 \\
\hline Impurity-76 & $100 \%$ & $0 \%$ & $7 \%$ & $0 \%$ & 27 & 2 \\
\hline
\end{tabular}


--continued--

\begin{tabular}{|c|c|c|c|c|c|c|}
\hline A0/Ce & Pyrochlore & Brannerite & Rutile & Zirconolite & TBE & Sinter \\
\hline Impurity-77 & $100 \%$ & $0 \%$ & $8 \%$ & $5 \%$ & 28 & 2 \\
\hline Impurity-78 & $100 \%$ & $0 \%$ & $12 \%$ & $0 \%$ & 29 & 2 \\
\hline Impurity-79 & $100 \%$ & $4 \%$ & $12 \%$ & $0 \%$ & 30 & 2 \\
\hline Impurity-80 & $18 \%$ & $0 \%$ & $10 \%$ & $0 \%$ & centroid & 2 \\
\hline Impurity-81 & $100 \%$ & $5 \%$ & $11 \%$ & $0 \%$ & 31 & 3 \\
\hline Impurity-82 & $100 \%$ & $0 \%$ & $13 \%$ & $0 \%$ & 32 & 3 \\
\hline Impurity-83 & $100 \%$ & $5 \%$ & $13 \%$ & $5 \%$ & 33 & 3 \\
\hline Impurity-84 & $100 \%$ & $8 \%$ & $11 \%$ & $0 \%$ & 34 & 3 \\
\hline Impurity-85 & $100 \%$ & $9 \%$ & $13 \%$ & $5 \%$ & 35 & 3 \\
\hline Impurity-86 & $100 \%$ & $15 \%$ & $21 \%$ & $5 \%$ & 36 & 3 \\
\hline Impurity-87 & $100 \%$ & $6 \%$ & $12 \%$ & $0 \%$ & 37 & 3 \\
\hline Impurity-88 & $100 \%$ & $10 \%$ & $13 \%$ & $0 \%$ & 38 & 3 \\
\hline Impurity-89 & $100 \%$ & $6 \%$ & $12 \%$ & $0 \%$ & 39 & 3 \\
\hline Impurity-90 & $100 \%$ & $3 \%$ & $14 \%$ & $5 \%$ & 40 & 3 \\
\hline Impurity-91 & $100 \%$ & $5 \%$ & $11 \%$ & $0 \%$ & 41 & 3 \\
\hline Impurity-92 & $100 \%$ & $3 \%$ & $12 \%$ & $0 \%$ & 42 & 3 \\
\hline Impurity-93 & $100 \%$ & $9 \%$ & $14 \%$ & $0 \%$ & 43 & 3 \\
\hline Impurity-94 & $100 \%$ & $7 \%$ & $14 \%$ & $0 \%$ & 44 & 3 \\
\hline Impurity-95 & $100 \%$ & $13 \%$ & $15 \%$ & $0 \%$ & 45 & 3 \\
\hline Impurity-96 & $100 \%$ & $6 \%$ & $13 \%$ & $0 \%$ & centroid & 3 \\
\hline
\end{tabular}

Standard models and analysis techniques for mathematically independent variables can be used to study the data from mixture-amount experiments such as this impurity study. ${ }^{4}$ The stepwise regression platform of JMP® was used to select a subset of effects for modeling each response as a function of the fifteen impurities. This subset was selected from a set of candidate effects that included each individual impurity ties and each pair-wise interaction (i.e. 121 candidate terms including the intercept). No theory associated with porosity or phase assemblage was used to guide the selection of terms to model. With this approach, the significant levels on the statistics for the resulting models are somewhat questionable since the statistical testing is not being conducted within the framework of a fixed model. However, the stepwise regression approach has been of practical use for over 30 years in helping trim out models to predict many kinds of responses. ${ }^{5}$ Table XX is a summary of the stepwise regressions in the form of groupings of the effects as "increasers" or "decreasers" of apparent porosity. Table XXI is a summary of the stepwise regressions in the form of groupings of the effects as "increasers" or "decreasers" of the phases investigated. 
Table XX. Model Parameters for Apparent Porosity Ranked by Significance.

\begin{tabular}{|c|c|}
\hline \multicolumn{2}{|c|}{ Apparent Porosity } \\
\hline Increasers & Decreasers \\
\hline $\mathrm{MoO}_{3} * \mathrm{P}_{2} \mathrm{O}_{5}$ & $\mathrm{ZnO}^{*} \mathrm{Na}_{2} \mathrm{O}$ \\
\hline $\mathrm{B}_{2} \mathrm{O}_{3}$ & $\mathrm{WO}_{3} * \mathrm{NaCl}$ \\
\hline $\mathrm{MoO}_{3} * \mathrm{NaCl}$ & $\mathrm{Na}_{2} \mathrm{O} * \mathrm{PbO}$ \\
\hline $\mathrm{P}_{2} \mathrm{O}_{5}$ & $\mathrm{CaCl}_{2} * \mathrm{PbO}$ \\
\hline$\overline{\mathrm{K}_{2} \mathrm{O}} * \mathrm{PbO}$ & $\mathrm{NaCl}$ \\
\hline $\mathrm{PbO}$ & \\
\hline $\mathrm{MoO}_{3}$ & \\
\hline $\mathrm{KCl}$ & \\
\hline$\overline{\mathrm{KCl}} * \mathrm{WO}_{3}$ & \\
\hline $\mathrm{NaCl}^{*} \mathrm{~B}_{2} \mathrm{O}_{3}$ & \\
\hline $\mathrm{CaCl}_{2} * \mathrm{WO}_{3}$ & \\
\hline $\mathrm{Na}_{2} \mathrm{O}$ & \\
\hline $\mathrm{WO}_{3}$ & \\
\hline $\mathrm{K}_{2} \mathrm{O}$ & \\
\hline $\mathrm{CaCl}_{2}$ & \\
\hline $\mathrm{ZnO}$ & \\
\hline
\end{tabular}

Table XXI. Model Parameters for Brannerite, Rutile and Zirconolite Ranked by Significance.

\begin{tabular}{|c|c|c|c|c|c|}
\hline \multicolumn{2}{|c|}{ Brannerite } & \multicolumn{2}{|c|}{ Rutile } & \multicolumn{2}{|c|}{ Zirconolite } \\
\hline Increasers & decreasers & Increasers & decreasers & Increasers & decreasers \\
\hline $\mathrm{P}_{2} \mathrm{O}_{5}$ & $\mathrm{ZnO}^{*} \mathrm{MoO}_{3}$ & $\mathrm{ZnO}$ & $\mathrm{KCl}^{*} \mathrm{ZnO}$ & $\mathrm{Na}_{2} \mathrm{O}$ & $\mathrm{ZnO}^{*} \mathrm{Na}_{2} \mathrm{O}$ \\
\hline $\mathrm{MoO}_{3}$ & $\mathrm{P}_{2} \mathrm{O}_{5} * \mathrm{NaCl}$ & $\mathrm{KCl} * \mathrm{P}_{2} \mathrm{O}_{5}$ & $\mathrm{ZnO}^{*} \mathrm{MgF}_{2}$ & $\mathrm{ZnO}$ & $\mathrm{ZnO}^{*} \mathrm{CaF}_{2}$ \\
\hline $\mathrm{ZnO}$ & $\mathrm{NaCl} * \mathrm{MgCl}_{2}$ & $\mathrm{MgCl}_{2}$ & $\mathrm{~B}_{2} \mathrm{O}_{3}$ & $\mathrm{~K}_{2} \mathrm{O}$ & $\mathrm{K}_{2} \mathrm{O}^{*} \mathrm{WO}_{3}$ \\
\hline $\mathrm{PbO}$ & $\mathrm{ZnCl}_{2} * \mathrm{PbO}$ & $\mathrm{B}_{2} \mathrm{O}_{3}{ }^{*} \mathrm{PbO}$ & $\mathrm{PbO}$ & $\mathrm{CaCl}_{2} * \mathrm{MgF}_{2}$ & $\mathrm{Na}_{2} \mathrm{O} * \mathrm{MgCl}_{2}$ \\
\hline$\overline{\mathrm{ZnCl}_{2}}$ & $\mathrm{~K}_{2} \mathrm{O}$ & $\mathrm{MgF}_{2}$ & $\overline{\mathrm{K}_{2} \mathrm{O}}$ & $\mathrm{P}_{2} \mathrm{O}_{5} * \mathrm{Na}_{2} \mathrm{O}$ & $\mathrm{CaF}_{2}{ }^{*} \mathrm{PbO}$ \\
\hline $\mathrm{WO}_{3}$ & $\mathrm{MgF}_{2} * \mathrm{CaF}_{2}$ & $\mathrm{KCl}^{*} \mathrm{~B}_{2} \mathrm{O}_{3}$ & $\mathrm{KCl}$ & $\mathrm{MgF}_{2}{ }^{*} \mathrm{CaF}_{2}$ & $\mathrm{~K}_{2} \mathrm{O} * \mathrm{~B}_{2} \mathrm{O}_{3}$ \\
\hline $\mathrm{MgF}_{2}$ & $\mathrm{MoO}_{3} * \mathrm{ZnCl}_{2}$ & $\mathrm{MoO}_{3}{ }^{*} \mathrm{~K}_{2} \mathrm{O}$ & $\mathrm{MoO}_{3}$ & $\mathrm{MgF}_{2}{ }^{*} \mathrm{PbO}$ & $\overline{\mathrm{K}_{2}} \mathrm{O}^{*} \mathrm{NaCl}$ \\
\hline $\mathrm{NaCl}$ & $\mathrm{ZnO} * \mathrm{PbO}$ & $\mathrm{ZnCl}_{2}$ & $\mathrm{P}_{2} \mathrm{O}_{5}$ & $\mathrm{ZnO}^{*} \mathrm{~K}_{2} \mathrm{O}$ & $\mathrm{K}_{2} \mathrm{O}^{*} \mathrm{CaCl}_{2}$ \\
\hline $\mathrm{CaCl}_{2}$ & $\mathrm{CaCl}_{2} * \mathrm{WO}_{3}$ & $\overline{\mathrm{K}_{2}} \mathrm{O}^{*} \mathrm{NaCl}$ & $\mathrm{NaCl}$ & $\mathrm{Na}_{2} \mathrm{O}^{*} \mathrm{CaF}_{2}$ & $\mathrm{~K}_{2} \mathrm{O} * \mathrm{PbO}$ \\
\hline $\mathrm{MgCl}_{2}$ & $\mathrm{P}_{2} \mathrm{O}_{5}{ }^{*} \mathrm{Na}_{2} \mathrm{O}$ & $\mathrm{MoO}_{3}{ }^{*} \mathrm{PbO}$ & & $\mathrm{CaCl}_{2}$ & $\mathrm{KCl}^{*} \mathrm{MoO}_{3}$ \\
\hline & $\mathrm{CaCl}_{2} * \mathrm{MgF}_{2}$ & & & & $\mathrm{~B}_{2} \mathrm{O}_{3}$ \\
\hline & $\mathrm{Na}_{2} \mathrm{O}$ & & & & $\mathrm{NaCl}$ \\
\hline & $\mathrm{P}_{2} \mathrm{O}_{5} * \mathrm{~K}_{2} \mathrm{O}$ & & & & $\mathrm{KCl}$ \\
\hline & $\mathrm{CaF}_{2}$ & & & & $\mathrm{MoO}_{3}$ \\
\hline & & & & & $\mathrm{P}_{2} \mathrm{O}_{5}$ \\
\hline & & & & & $\mathrm{MgCl}_{2}$ \\
\hline & & & & & $\mathrm{PbO}$ \\
\hline & & & & & $\mathrm{MgF}_{2}$ \\
\hline & & & & & $\mathrm{CaF}_{2}$ \\
\hline & & & & & $\mathrm{WO}_{3}$ \\
\hline
\end{tabular}


Two of the compositions, Impurity- 84 and -89 , were produced using the A0 baseline composition (Pu and $\mathrm{U}$ ). Three pellets of each composition were pressed and sintered as in the previous small pellets. Figure 2 is a photograph of an Impurity-89 and an Impurity-84 pellet with an $\mathrm{A} 0$ baseline pellet for comparison. Significant cracking was observed in all of the impurity pellets made with plutonium. However, none of the cracking was serious enough to cause spalling. Although the pellets remained monolithic, Archimedes density was forgone in favor of geometric density to preserve the integrity of the pellets for potential future performance testing. Table XXII is the average bulk density determined by geometric measurements and the average percent shrinkage of the plutonium bearing impurity pellets. As with all previous experiments with elevated levels of molybdenum, densification was limited resulting in a high apparent porosity relative to other compositions. The pellets made with maximum levels of phosphorus resulted in lower porosities than previously observed with this composition. The lower porosity may be due to enhanced mixing that is part of the plutonium pellet fabrication in a glovebox. Phosphorus pentoxide can be difficult to admix with dry powders to produce a homogeneous product and can lead to spurious results.
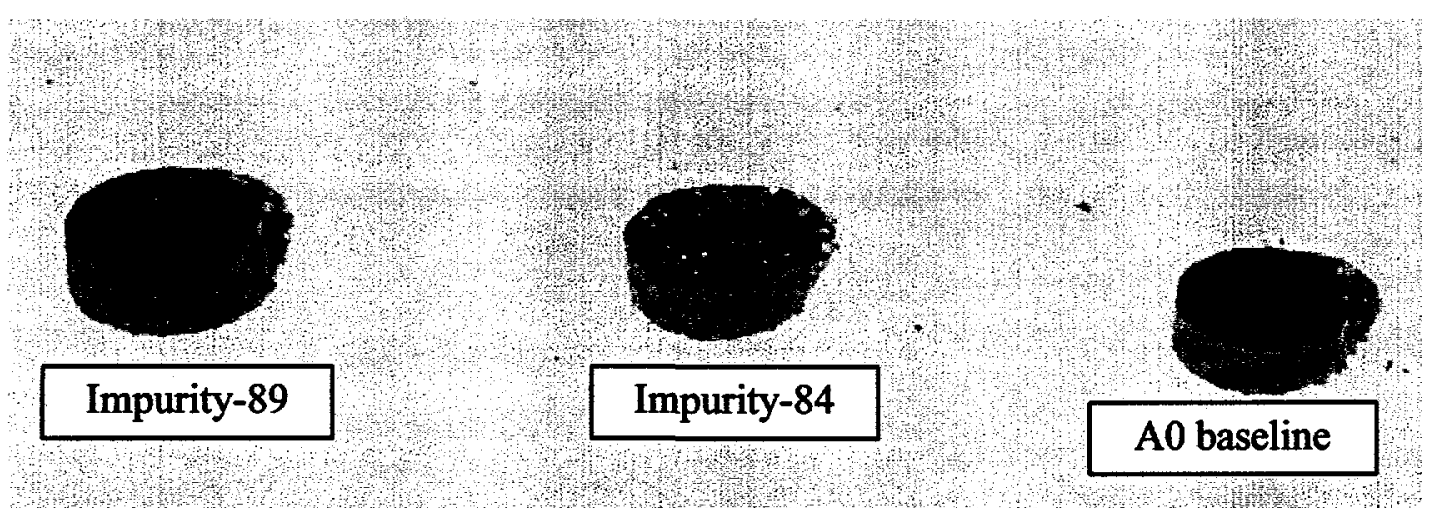

Figure 2. Photograph of an Impurity-89 and an Impurity-84 pellet with an A0 baseline pellet for comparison.

Table XXII. Average Bulk Density and Percent Shrinkage for Plutonium Bearing Impurity Pellets.

\begin{tabular}{|c|c|c|}
\hline Plutonium & Bulk Density & Shrinkage \\
\hline Pellet ID & $\left(\mathrm{g}^{\mathrm{c}} \mathrm{cm}^{3}\right)$ & $(\%)$ \\
\hline Impurity-84 & 4.59 & 17.53 \\
\hline Impurity-89 & 3.40 & 9.67 \\
\hline
\end{tabular}

X-ray diffraction analysis of the two impurity compositions revealed similar results. In both cases, the primary phase was pyrochlore with minor amounts of brannerite and rutile. Impurity-84 also showed trace amounts of zirconolite. Evidence of the vitreous phase detected in the non-radioactive Impurity-84 composition was not present in the plutonium bearing pellet of the same composition. 
WSRC-TR-99-00479

Revision: 0

\section{Conclusions}

\section{Phase I}

In Phase I of the study, fifteen volatile impurities were individually added to the baseline ceramic form composition, A0, and two compositional extremes, B3-7 and B3-8.

\section{Non-Radioactive}

The apparent porosity of the all three compositions was only slightly sensitive to single impurity additions. Additions of $\mathrm{MoO}_{3}$ and $\mathrm{WO}_{3}$ raised the porosity of $\mathrm{B} 3-7 \mathrm{~s}$ above ten percent. Additions of $\mathrm{P}_{2} \mathrm{O}_{5}$ to $\mathrm{B} 3-8 \mathrm{~s}$ had a similar effect. The influence of impurity additions to the apparent porosity of the $\mathrm{A} 0 / \mathrm{Ce} / \mathrm{s}$ composition was not statistically significant.

In the $\mathrm{A} 0$ and $\mathrm{B} 3-7 \mathrm{~s}$ compositions, unacceptable amounts of perovskite were present in pellets made with $\mathrm{Na}_{2} \mathrm{CO}_{3}$. All other phases present were in acceptable amounts as described in Reference 1. In the B3-8s pellets, no brannerite was observed either in the reference composition or in any of the impurity compositions. The brannerite phase does not readily form with cerium as the surrogate for uranium.

\section{Actinide}

The apparent porosity of the three base compositions made with cerium and uranium and one with thorium and uranium was influenced by impurities more than their non-radioactive counterparts. This may be due in part to the differences in phase assemblage produced when actinides are used. The non-radioactive pellets, along with pyrochlore as the primary phase, contained zirconolite and perovskite. The pellets made with actinides usually had brannerite as a recurring phase (pyrochlore is the primary phase) with reduced amounts of zirconolite and little or no perovskite.

Many of the impurities increased the apparent porosity of several of the compositions above ten percent. Most notably $\mathrm{B}_{2} \mathrm{O}_{3}, \mathrm{P}_{2} \mathrm{O}_{5}$ and $\mathrm{MoO}_{3}$ greatly increased the apparent porosity of the base compositions. When potassium was added to the B3-8 composition as either the chloride or the hydroxide the sintered pellets disintegrated after setting out for several hours. This was not the case with other chloride and hydroxide compounds nor was it a problem in other base compositions.

All four of the base compositions tested with impurities resulted in phase assemblages and abundance within the acceptable range in Reference 1 . The only uncommon observance was the drastic reduction in brannerite in the $\mathrm{A} 0 / \mathrm{Ce}$ composition with potassium as $\mathrm{KOH}$.

\section{Phase II}

In Phase II of the study, fifteen volatile impurities were added to the baseline ceramic form composition, $\mathrm{A} 0$, in varying ratios that totaled either 0.6 or 0.8 moles of impurities per mole of plutonium (Ce). 
WSRC-TR-99-00479

Revision: 0

\section{Non-Radioactive}

The non-radioactive baseline composition, $\mathrm{A} 0 / \mathrm{Ce} / \mathrm{s}$, was relatively unaffected by mixtures representing both 0.6 and 0.8 moles of volatile impurities per mole of plutonium $(\mathrm{Ce})$. The highest apparent porosity measured in the 96 compositions was less than ten percent $(7.23 \%$, Impurity-82, TBE-32). Similarly, the XRD results showed no significant variance from the reference mineralogy.

When select pellets were scaled up to $\sim 115 \mathrm{~g}$, a significant increase in apparent porosity was noted in one composition, Impurity-89 (TBE-39). The main impurity in the Impurity-89 composition is $\mathrm{MoO}_{3}$. X-ray diffraction analysis of the large pellets indicate that a vitreous phase may be present in the Impurity-84 composition which contains the study's maximum quantities of phosphorus and elevated quantities of boron and fluorine. No crystalline phosphate phase was detected by XRD. When other glass formers such as silica and boron are present, the phosphorus partitions preferentially into the vitreous phase over crystalline phase.

\section{Actinide}

The results from the statistical analyses performed suggest rather complex behavior in the modeling of these responses as functions of these possible impurities. There appear to be significant interactions among these impurities that affect the apparent porosity and the phase assemblage of these compositions. However, the data available are not sufficient for a definitive assessment as to the importance of all possible pairs of interactions.

Future work will concentrate on identifying two factor interactions through a reduction in variables tested and careful selection of compositions tested.

\section{Summary}

The effect of fifteen volatile impurities on the apparent porosity and mineralogy of the plutonium ceramic form were investigated. The impurities were added singly to three compositions. First using cerium as a surrogate for both plutonium and uranium and then only as a surrogate for uranium. Archimedes density and x-ray diffraction analysis were used to determine the relative effects of the individual impurities. Subsequent experimentation involved adding all fifteen impurities in different ratios to the target ceramic composition. Impurity compositions used were statistically developed to provide maximum information for the number of compositions investigated. The total amount of the impurities added was 0.8 moles of impurities per mole of plutonium. In all but the final two tests, the plutonium was represented by an equimolar amount of cerium. $\mathrm{B}_{2} \mathrm{O}_{3}, \mathrm{P}_{2} \mathrm{O}_{5}$ and $\mathrm{MoO}_{3}$ all were determined to significantly increase the apparent porosity of the ceramic form. $\mathrm{ZnO}$ additions increased the propensity of zirconolite formation.

Large pellets were produced from three impurity compositions to determine the effect of scale on the apparent porosity and mineralogy of the ceramic form. The influence of scale on 
the apparent porosity was inconclusive. For two compositions, the apparent porosity did not change significantly, but for the third composition the apparent porosity increased greatly. Scale did not show any effect on the mineralogy of any of the compositions examined.

Two impurity compositions made with plutonium using the target ceramic composition showed little variation in the apparent porosity. The differences in the mineralogy were consistent with those seen with undoped ceramic forms (i.e. perovskite in cerium pellets and brannerite in plutonium pellets).

The mineralogy of the pyrochlore based ceramic form is tolerant of a broad range of impurities. Fifteen volatile impurities were added individually and concurrently to the ceramic form composition. In the actinide compositions tested that were made with cerium as a surrogate for plutonium, there was no $x$-ray diffraction evidence of objectionable quantities of secondary phases as specified in Reference 1. The apparent porosity of the ceramic form is somewhat sensitive to multiple impurity additions. In this study, apparent porosity is used as an indication of sintering effects. Densification, as measured by apparent porosity, was significantly affected by eleven of the fifteen impurities. Several two-factor interactions were significant in either increasing or decreasing the apparent porosity of the ceramic. However, the data were not sufficient for a definitive assessment of the importance of the interactions

\section{Future Work}

The results of this study will be incorporated with the results from the other participating laboratories to fulfill Plutonium Immobilization Program milestone 3.3-1. The future work put forward from these results include:

- Develop representative compositions, based upon current knowledge of the plutonium feed specifications, for each of the impurity categories that were developed from impurity equivalency testing.

- Develop a statistically designed series of experiments to determine interactions among the impurity categories and the subsequent effect on apparent porosity and phase assemblage.

- Produce small non-radioactive pellets (SRTC), full-scale non-radioactive pucks (SRTCCPTF), small Pu-U pellets (SRTC), full-scale Ce-U pucks (LLNL), and select full scale Pu-U pucks (LLNL-PuCTF).

- Perform quantitative microscopic analysis of the phases formed in select impurity compositions from the experimental design.

- Use results to provide input into the Product Control Model. 


\section{References}

${ }^{1}$ B.B. Ebbinghaus, C.A. Cicero-Herman, L. Gray, and H.F. Shaw, "PIP Baseline Formulation," DOE Report PIP-99-012 (1999).

${ }^{2}$ Cozzi, A. D., "Volatile Impurity Study: Technical Task \& QA Plan," WSRC-RP-98-01320, Rev. 0, December 3, 1998.

${ }^{3}$ Pareizs, J.M. and Cozzi, A.D., "Effect of Uranium Oxidation State and Sintering Atmosphere on Phase Formation of the Ceramic Wasteform for Plutonium Disposition," WSRC-MS-98-00837, July 1999.

${ }^{4}$ Piepel, G.F. and Cornell, J.A., "Models for Mixture Experiments When the Response Depends on the Total Amount," Technometrics, pp. 219-227, August 1985.

${ }^{5}$ SAS Institute, Inc., JMP Statistics and Graphics Guide, Version 3, SAS Institute Inc., Cary, NC, 1994. 
APPENDIX A

MEMO REQUESTING EXPERIMENTAL DESIGN 
J. C. Marra, 773-43A

K. E. Mottel, 773-43A

W. F. Ayres, 773-41A

K. A. Howard, 773-43A

To:

T. B. Edwards, 773-42A

K. G. Brown, 704-1T

From:

A. D. Cozzi, 773-43A

\section{REQUEST FOR EXPERIMENTAL DESIGN FOR PLUTONIUM IMMOBILIZATION PROGRAM (PIP) IMPURITY STUDY (U)}

\section{INTRODUCTION}

Approximately 18 of the 50 metric tons of plutonium identified for disposition contain significant quantities of impurities. A ceramic waste form is the chosen option for immobilization of the excess plutonium. The compositions and the amounts of impurities to be examined were set by the Lawrence Livermore National Laboratory (LLNL) Technical Lead for Form Development, Bart Ebbinghaus, as shown in Appendix I. Table I lists the three compositions that will be used in the impurity study. These compositions will be the base compositions to which the impurities will be added. Cerium oxide is used as the surrogate for uranium oxide and plutonium oxide for the non-radioactive surrogate work. In future experiments, cerium oxide will be used only as a surrogate for plutonium oxide for the radioactive surrogate experiments. A select subset of these compositions may be prepared using both uranium oxide and plutonium oxide.

Table I. Base Compositions for the Volatile Impurity Study.

\begin{tabular}{|c|c|c|c|}
\hline \multirow{2}{*}{ Raw Material } & \multicolumn{3}{|c|}{ Composition in Mol Percent } \\
\cline { 2 - 4 } & $\mathrm{A} 0 / \mathrm{Ce} / \mathrm{s}^{\dagger}$ & $\mathrm{B} 3-7 \mathrm{~s}^{\dagger}$ & $\mathrm{B3}-8 \mathrm{~s}^{\top}$ \\
\hline $\mathrm{CaO}$ & 21.37 & 19.96 & 13.29 \\
\hline $\mathrm{TiO} \mathrm{O}_{2}$ & 54.05 & 51.35 & 59.13 \\
\hline $\mathrm{HfO}_{2}$ & 6.09 & 13.94 & 6.02 \\
\hline $\mathrm{Gd}_{2} \mathrm{O}_{3}$ & 2.64 & 2.21 & 2.23 \\
\hline $\mathrm{CeO}_{2}\left(\mathrm{UO}_{2}\right)$ & 10.56 & 6.91 & 13.22 \\
\hline $\mathrm{CeO}_{2}\left(\mathrm{PuO}_{2}\right)$ & 5.28 & 4.28 & 6.11 \\
\hline $\mathrm{Al}_{2} \mathrm{O}_{3}$ & 0.00 & 1.35 & 0.00 \\
\hline Total & 99.99 & 100.00 & 100.00 \\
\hline
\end{tabular}

\footnotetext{
" $\mathrm{A} 0$ is the baseline formulation and targets the preferred composition. The " $\mathrm{Ce}$ " designation indicates a ceria substitution for plutonium oxide on a molar basis. B3-7 is a compositional extreme that targets a zirconolite-rich primary phase and uses ceria as a surrogate for plutonium oxide on a molar basis. B3-8 is a compositional extreme that targets a branneriterich primary phase and, like B3-7, uses ceria as a surrogate for plutonium.
}

'The "/s" designation indicates a ceria substitution for uranium oxide on a molar basis. 


\section{EXPERIMENTAL}

For each of the three base compositions, sufficient powder was produced following GTPU-3-005, Rev. 0 to make three pellets for each of the fifteen impurities added individually in each composition. Three pellets also were made with no impurities added to provide a reference apparent porosity and $\mathrm{x}$-ray diffraction pattern. This resulted in 48 pellets for each of the three base compositions ( 3 pellets $x$ ( 15 impurities +1 base)). To make three pellets with a single impurity, 6.5 grams of the base powder was weighed out and set aside. The amount of the impurity was calculated from the mole percent ceria as plutonium oxide in Table I. A small amount of the base powder was co-ground with the impurity using an alumina mortar and pestle. The mixed/ground powders were added back to the remnants of the 6.5 grams of base powder and mixed on a roller mill. The mixed powder was divided and used to press three pellets $\sim 2$ grams each. The pellets were sintered according to GTPU-3-005, Rev. 0. Criteria for pellet acceptability have not yet been finalized. Preliminary criteria are an apparent porosity $<10 \%$ and mineralogy similar to the baseline for that particular composition. The apparent porosity was determined for all pellets using the Archimedes method. The mineralogy was determined for one pellet from each impurity composition using $\mathrm{x}$-ray diffraction. If an impurity composition did not satisfy both of the preliminary acceptance criteria, the samples were remade with a reduced amount of the impurity. This was repeated until both of the preliminary acceptance criteria were satisfied. Table II shows the amount of each impurity added individually that can be incorporated into each of the three compositions while satisfying the preliminary acceptance criteria.

Table II. Ratio of Mols Impurity/Mols Plutonium that Satisfy Preliminary Acceptance Criteria.

\begin{tabular}{|c|c|c|c|}
\hline & \multicolumn{3}{|c|}{ Base Composition } \\
\hline Impurity & $\mathrm{A} 0 / \mathrm{s}$ & B3-7s & B3-8s \\
\hline Oxides & (s) & - & $\sqrt{4}$ \\
\hline $\mathrm{B}_{2} \mathrm{O}_{3}$ & 0.6 & 0.6 & 0.6 \\
\hline $\mathrm{MoO}_{3}$ & 0.6 & 0.45 & 0.6 \\
\hline $\mathrm{WO}_{3}$ & 0.6 & 0.5 & 0.6 \\
\hline $\mathrm{ZnO}$ & 0.6 & 0.6 & 0.6 \\
\hline $\mathrm{PbO}$ & 0.6 & 0.6 & 0.6 \\
\hline $\mathrm{Na}_{2} \mathrm{O}$ & $\overline{0.6}$ & 0.6 & 0.6 \\
\hline $\mathrm{K}_{2} \mathrm{O}$ & 0.6 & 0.6 & 0.6 \\
\hline $\mathrm{P}_{2} \mathrm{O}_{5}$ & 0.6 & 0.6 & 0.6 \\
\hline Chlorides & 97 & 20 - & 20 \\
\hline $\mathrm{CaCl}_{2}$ & 0.6 & 0.6 & 0.6 \\
\hline $\mathrm{MgCl}_{2}$ & 0.6 & 0.6 & 0.6 \\
\hline $\mathrm{ZnCl}_{2}$ & 0.6 & 0.6 & 0.6 \\
\hline $\mathrm{NaCl}$ & 0.6 & 0.6 & 0.6 \\
\hline $\mathrm{KCl}$ & 0.6 & 0.6 & 0.6 \\
\hline Fluorides & & 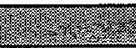 & Yry \\
\hline $\mathrm{CaF}_{2}$ & 0.6 & 0.6 & 0.6 \\
\hline $\mathrm{MgF}_{2}$ & 0.6 & 0.6 & 0.6 \\
\hline
\end{tabular}

It is expected that the range of occurrence of any of the impurity materials will range from $0-0.6 \mathrm{~mol}$ per mol of plutonium. There is the ability to produce 50 - 60 unique impurity combinations for each of the three base compositions. The data for the maxima have already been generated.

\section{CONCLUSIONS}

Based upon the results obtained, it is requested that the Statistical Consulting Section (SCS) provide an experimental design that can be used to determine if there exist any first-order interactions among the fifteen impurities that influence the preliminary acceptability criteria discussed. An additional constraint for the multiple impurity samples is the maximum of 0.6 moles of total impurity per mol of plutonium. It is understood that to determine the extrema, orderly additions and subtractions of impurities were made and that the circumstances under which the samples were produced (using various personnel over a considerable time period) may provide additional uncertainty to the results. 


\section{APPENDIX I}

Guidelines For Volatile Impurity Submatrix

Author: ebbinghaus101inl.gov at Mailhub

Date: 6/22/98 3:05 PM

BCC: ALEX COZZI at SRCCCO8

TO: james.marra at Mailhub

To: john.pareizs at Mailhub

TO: alex.cozzi at Mailhub

Alex, John, and Jim,

The following is some guidance that I hope will help you is designing your impurity-volatiles tests matrix.

Volatile Impurities

Pximary Importance Secondary Importance

B01.5

$\mathrm{CaCl2}$

Koo. 5

$\mathrm{NaOO.5}$

CaF2

KCl

$\mathrm{PO} 2.5$

$\mathrm{MgCl} 2$

$\mathrm{PbO}$

MgF2

ZnCl2

MOO2, 1003

$\mathrm{VaCl}$

WO2, WO3

zno

Composition

Testing should be performed primarily on the baseline composition $(A-0)$. some tests with zirconolite-rich $(\mathrm{B3}-3 / 7)$ or pyrochlore-rich material (B3-4/8) are also desirable. Other compostions are your choice.

Pu vs. Surrogates

I think most of the work can be performed with one or more surrogate compositions (e.g. Hf-Ce-U, HE-Ce-Ce, Hf-Th-U, etc) with a small fraction repeated with actual plutonium compositions.

Loading

Loadings around 0.6 moles of volatiles per mole of puo2 or surrogate should be perfomed. This ratio corresponds to the maximum feed specification.

other ratios are up to you.

Fabrication

You should try to get some idea of sample size effects. Note also that preparation of samples in aix needs to be conducted carefully. Some of the impurites are very hydroscopic which could mess up the results.

Hope this helps rather than confuses. Bart $\mathbf{E}$. 


\section{APPENDIX B}

\section{MEMO OUTLINING TEST MATRIX}


April 6, 1999

To: A. D. Cozzi, 773-43A

cc: K. G. Brown, 704-1T

J. W. Congdon, 773-A

S. P. Harris, 773-42A (es)

E. W. Holtzscheiter, 773-A (es)

D. T. Rankin, 773-A

R. C. Tuckfield, 773-42A

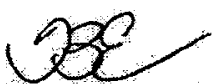

From: T. B. Edwards, $773-42$ A (5-5148)

es - executive summary only

Statistical Consulting Section
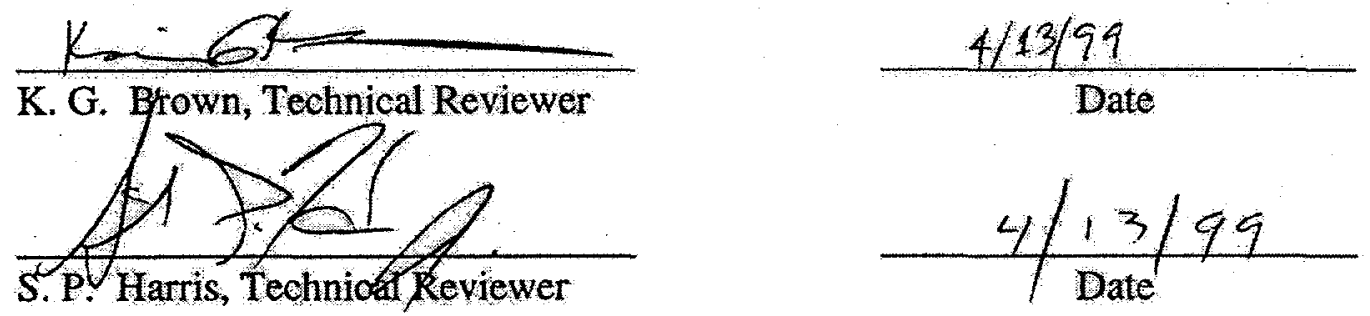

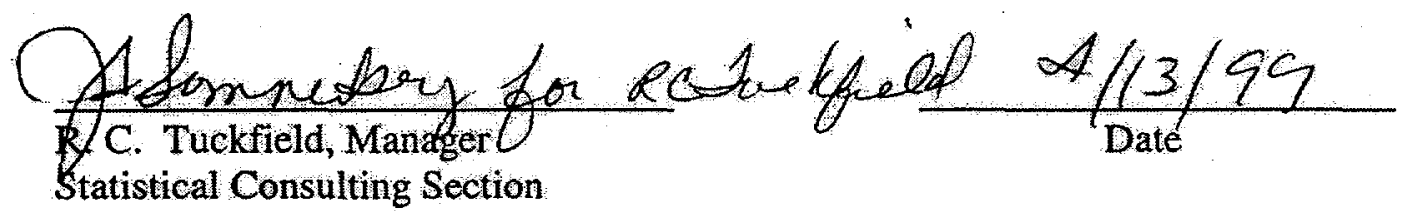

Test MATRIX FOR

Volatile IMPURITY STUdY IN

Support OF THE Pu ImMobilization

TASK (U) 


\section{EXECUTIVE SUMMARY}

The Statistical Consulting Section is responsible for developing the test matrix for the second phase study for the evaluation of volatile species, a subtask of the impurity task of the plutonium $(\mathrm{Pu})$ immobilization form development program.

This memorandum is in response to the request for this test matrix. A test matrix of 48 impurity combinations (including three check "standards") has been provided for testing against each of the three base compositions. These impurity combinations should be tested in a random sequence for each base composition. 


\section{INTRODUCTION}

A task technical and quality assurance (TT\&QA) plan for the evaluation of volatile species, a subtask of the impurity task of the plutonium $(\mathrm{Pu})$ immobilization form development program, has been issued [1]. This subtask has two major phases: the first phase involves the investigation of the impurities separately in the waste form and the second phase the effects of multiple impurities and their potential interactions on the properties of the waste form.

The Statistical Consulting Section is responsible for developing the test matrix for the second phase study. This memorandum is in response to the request for this test matrix [2].

\section{DISCUSSION}

There are three base compositions that are to be used in the impurity studies (these compositions are designated as $\mathrm{A} 0 / \mathrm{Ce} / \mathrm{s}, \mathrm{B} 3-7 \mathrm{~s}$, and $\mathrm{B} 3-8$ ), and the impurities are to be tested for each of these compositions [2]. The results of the first phase of testing provide limits on the individual amounts of the impurities (since they were tested separately during that test phase) that can be successfully incorporated into each of the three compositions while satisfying the preliminary acceptance criteria [2]. Table 1 provides these results (as a ratio of moles of impurity to moles of $\mathrm{Pu}$ ) for each impurity of interest.

Table 1: Ratio of Moles Impurity/Moles Pu

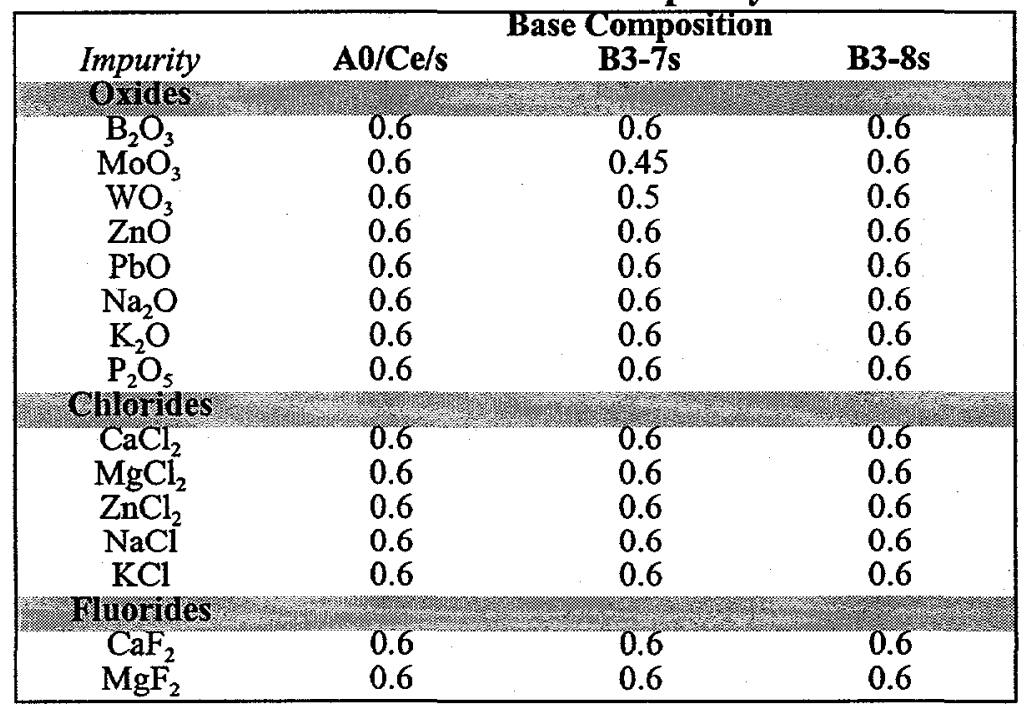

The request constrains the total impurity per mole of $\mathrm{Pu}$ to be no more than 0.6 mole [2]. Based upon Table 1, each of the three compositions can tolerate impurities of a single component up to that concentration level (except for B3-7s, which cannot tolerate more than 0.45 mole $\mathrm{MoO}_{3}$ or more than 0.5 mole $\mathrm{WO}_{3}$ per mole of $\mathrm{Pu}$ ). The objective of the phase 2 study is to investigate the potential for interactions among the impurities that lead to failure of the acceptance criteria at (total) impurity concentrations of less than or equal to 0.6 mole per mole of $\mathrm{Pu}$. However, the number of combinations of impurities tested for any single base composition is to be no more than 60 [2]. 
A combination of impurities that is to be added to one of the base compositions for testing may be considered as a mixture, and the investigation into the relationships between such a mixture and the acceptance criteria may be looked upon as a modeling problem. There are commercially available, statistical software tools to assist in the design and analysis of such problems even when interactions among the components must be explored. To be more specific, algorithms exist that can be used to generate a set of candidate compositions within the impurity-space consisting of these 15 components. Two such programs are SAS/QC ${ }^{\circledR}$ Software and JMP ${ }^{\circledR}$ both from SAS Institute, Inc. [3,4]. Computeraided, design-of-experiments routines are also available, which utilize one or more design optimality criteria, to choose a set of points (the design) from the candidate list of points. ${ }^{1}$ Almost all of these computer-aided design routines are model dependent. Once the form of the mixture model is chosen, such as a model relating a response of interest to a linear combination of the mixture components, and a list of candidate design points is specified, a particular design (of a designated size) can be selected from the candidate points that minimizes or maximizes a particular criterion. A final design may be selected from these designs of varying sizes using this same, and/or additional, criterion along with economic considerations.

Once again, these are model-dependent criteria, and a design that is optimal for one model form, for example a linear model, will not necessarily be optimal for another model such as a quadratic model. And it is a quadratic model that is necessary to explore for interactions among the mixture components, and, so, it would be the model form of choice for the impurity study. The size (number of impurity mixtures) necessary to generate the minimum amount of data needed to fit such a model would equal the number of terms to be estimated in the model. A quadratic model covering the impurity-space for these 15 components would contain $\left(\begin{array}{c}15 \\ 2\end{array}\right)=105$ pair-wise interaction terms alone. Add to this the individual terms and such a model would have 120 coefficients that need to be estimated. And this is just for one of the base composition types. Although the data collected from Phase 1 of this study could be used toward the 120 needed, the amount of additional data required to fit the quadratic model is still prohibitive.

Summarizing, the large number of impurities (15) involved in the requested analysis leads to a statistically-driven design's yielding a prohibitively large number of combinations of these impurities for testing. This problem is exacerbated further by the possibility of an outcome for any one of the impurity combinations to be unique to only one of the base compositions (as for the individual impact of $\mathrm{MoO}_{3}$ and $\mathrm{WO}_{3}$ in Table 1). Thus, the acceptability of any combination of impurities must be judged against all three base compositions.

Given that the traditional approach to designing this mixture experiment leads to prohibitively large test matrices, an approach that provides systematic (although somewhat limited) coverage of the impurity-space is offered. This approach requires spiking each of the 15 impurities in turn over a set of three mixture combinations, where all impurities are present at some positive concentration. Thus, there are $15 * 3=45$ combinations to be tested for each base composition, 
and these combinations are provided in Table 2. The impurity components are presented as weight percents, and their total equals 105 for each of the 45 combinations. Thus, if 105 grams for each impurity combination were needed, the information in Table 2 provides the number of grams of each impurity that is to be added to achieve the desired amount of each combination.

It is recommended that the mixture combination with each impurity comprising $1 / 15^{\text {th }}$ of the total (i.e., each at $7 \mathrm{wt} \%$ of the total 105) be used as a check "standard" as the combinations of Table 2 are tested against each base composition. The 45 combinations of Table 2 should be tested in a random sequence with the check "standard" being run at the beginning, middle, and end of the testing process for each base composition. This brings the total number of impurity combinations to be tested against each base composition to 48 . 
SRT-SCS-99-017

April 6, 1999

Page 6 of 7

Table 2: Impurity Combinations (as Weight Percents with their Total being 105)

\begin{tabular}{|c|c|c|c|c|c|c|c|c|c|c|c|c|c|c|c|c|}
\hline 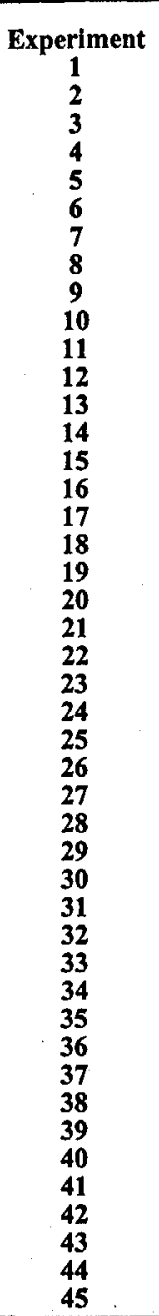 & 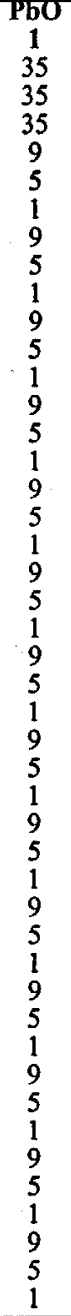 & 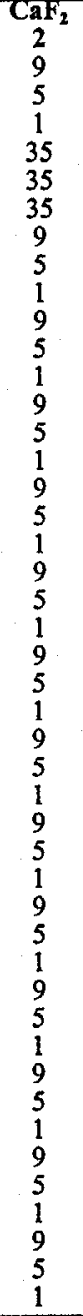 & $\begin{array}{c}B_{2} O_{3} \\
3 \\
9 \\
5 \\
1 \\
9 \\
5 \\
1 \\
35 \\
35 \\
35 \\
9 \\
5 \\
1 \\
9 \\
5 \\
1 \\
9 \\
5 \\
1 \\
9 \\
5 \\
1 \\
9 \\
9 \\
1\end{array}$ & 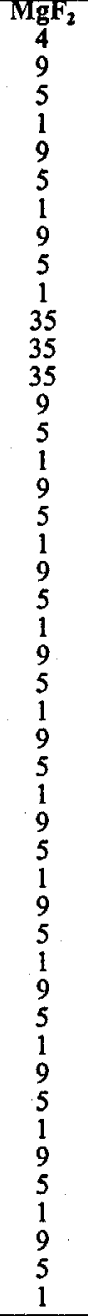 & $\begin{array}{c}\mathbf{M g C l}_{2} \\
\mathbf{5} \\
9 \\
5 \\
5 \\
1 \\
9 \\
5 \\
1 \\
9 \\
5 \\
1 \\
9 \\
5 \\
1 \\
35 \\
35 \\
35 \\
9 \\
5 \\
1 \\
9 \\
5 \\
1 \\
9 \\
5 \\
1 \\
9 \\
5 \\
1 \\
9 \\
5 \\
1 \\
9 \\
5 \\
1 \\
9 \\
5 \\
1 \\
9 \\
5 \\
1 \\
9 \\
5 \\
1 \\
9 \\
5 \\
1 \\
\end{array}$ & $\begin{array}{c}Z_{0} C_{2} \\
6 \\
9 \\
5 \\
1 \\
9 \\
5 \\
1 \\
9 \\
5 \\
1 \\
9 \\
5 \\
1 \\
9 \\
5 \\
1 \\
35 \\
35 \\
35 \\
9 \\
5 \\
1 \\
9 \\
5 \\
1 \\
9 \\
5 \\
1 \\
9 \\
5 \\
1 \\
9 \\
5 \\
1 \\
9 \\
5 \\
1 \\
9 \\
5 \\
1 \\
9 \\
5 \\
1 \\
9 \\
5 \\
1 \\
\end{array}$ & 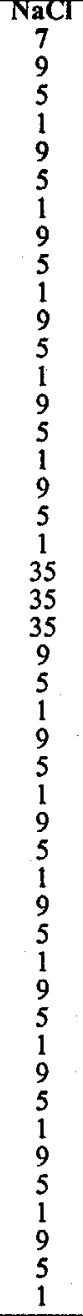 & 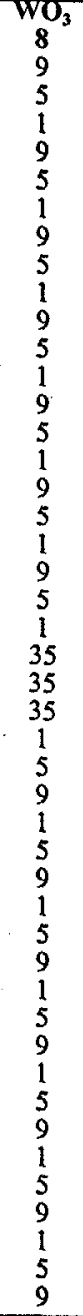 & 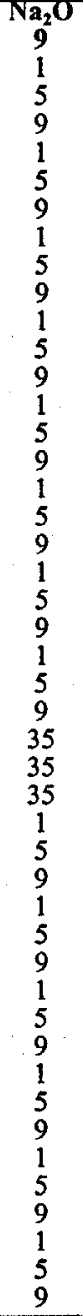 & $\begin{array}{c}C_{10} C_{2} \\
1 \\
5 \\
9 \\
9 \\
1 \\
5 \\
9 \\
1 \\
5 \\
9 \\
1 \\
5 \\
9 \\
1 \\
5 \\
9 \\
1 \\
5 \\
9 \\
1 \\
5 \\
9 \\
1 \\
5 \\
9 \\
1 \\
5 \\
9 \\
35 \\
35 \\
35 \\
1 \\
5 \\
9 \\
1 \\
5 \\
9 \\
1 \\
5 \\
9 \\
1 \\
5 \\
9 \\
1 \\
5 \\
9 \\
\end{array}$ & $\begin{array}{c}K_{2} 0 \\
11 \\
1 \\
5 \\
9 \\
1 \\
5 \\
9 \\
1 \\
5 \\
9 \\
1 \\
5 \\
9 \\
1 \\
5 \\
9 \\
1 \\
5 \\
9 \\
1 \\
5 \\
9 \\
1 \\
5 \\
9 \\
1 \\
5 \\
9 \\
1 \\
5 \\
9 \\
35 \\
35 \\
35 \\
1 \\
5 \\
9 \\
1 \\
5 \\
9 \\
1 \\
9 \\
9 \\
9 \\
1 \\
9 \\
9\end{array}$ & 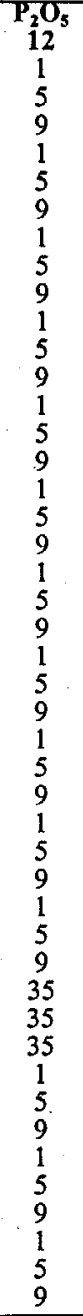 & $\begin{array}{c}M_{13} 0_{3} \\
1 \\
5 \\
9 \\
1 \\
5 \\
9 \\
1 \\
5 \\
9 \\
1 \\
5 \\
9 \\
1 \\
5 \\
9 \\
1 \\
5 \\
9 \\
1 \\
5 \\
9 \\
1 \\
1 \\
5 \\
9 \\
1 \\
5 \\
9\end{array}$ & $\begin{array}{c}70 \\
14 \\
1 \\
5 \\
9 \\
1 \\
5 \\
9 \\
1 \\
5 \\
9 \\
1 \\
5 \\
9 \\
1 \\
5 \\
9 \\
1 \\
5 \\
9 \\
1 \\
5 \\
9 \\
9 \\
0 \\
0\end{array}$ & 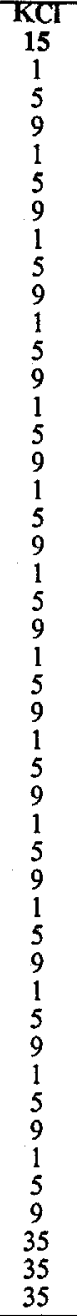 & $\begin{array}{l}\text { Total } \\
105 \\
105 \\
105 \\
105 \\
105 \\
105 \\
105 \\
105 \\
105 \\
105 \\
105 \\
105 \\
105 \\
105 \\
105 \\
105 \\
105 \\
105 \\
105 \\
105 \\
105 \\
105 \\
105 \\
105 \\
105 \\
105 \\
105 \\
105 \\
105 \\
105 \\
105 \\
105 \\
105 \\
105 \\
105 \\
105 \\
105 \\
105 \\
105 \\
105 \\
105 \\
105 \\
105 \\
105 \\
105\end{array}$ \\
\hline
\end{tabular}

$\infty$ 


\section{CONCLUDING COMMENTS}

A test matrix of 48 impurity combinations (including the three check "standards") has been provided for testing against each of the three base compositions. These impurity combinations should be tested in a random sequence for each base composition. It is anticipated that each of these impurity combinations is to be tested at a concentration of 0.6 mole per mole of $\mathrm{Pu}$. For B3-7s, the three mixture combinations spiked with $\mathrm{MoO}_{3}$ and $\mathrm{WO}_{3}$, if they fail at 0.6 mole, should be retested for acceptability at 0.45 and 0.5 mole, respectively, in deference to the results presented in Table 1.

\section{REFERENCE}

[1] Cozzi, A. D., "Volatile Impurity Study: Technical Task \& QA Plan," WSRC-RP-98-01320, Rev. 0, December 3, 1998.

[2] Cozzi, A. D., "Request for Experimental Design for Plutonium Immobilization Program (PIP) Impurity Study (U)," SRT-GFM-98-0038, January 26, 1999.

[3] SAS Institute, Inc., SAS/QC Software: Reference, Version 6, First Edition, SAS Institute, Inc., Cary, NC, 1990.

[4] SAS Institute, Inc., JMP Statistics and Graphics Guide, Version 3, SAS Institute, Inc., Cary, NC, 1994. 